\title{
A new potential approach to block HIV-1 replication via protein-protein interaction and strand-transfer inhibition
}

\author{
Stefania Ferro ${ }^{\mathrm{a}, *}$, Laura De Luca ${ }^{\mathrm{a}}$, Giuseppa Lo Surdo ${ }^{\mathrm{a}}$, Francesca Morreale ${ }^{\mathrm{a}}$, Frauke Christ ${ }^{\mathrm{b}}$, \\ Zeger Debyser ${ }^{\mathrm{b}}$, Rosaria Gitto ${ }^{\mathrm{a}}$, Alba Chimirri ${ }^{\mathrm{a}}$ \\ a Dipartimento di Scienze del Farmaco e dei Prodotti per la Salute, Università di Messina, Viale Annunziata, I-98168 Messina, Italy \\ ${ }^{\mathrm{b}}$ Molecular Virology and Gene Therapy, KU Leuven and IRC KULAK, Kapucijnenvoer 33, B-3000 Leuven, Flanders, Belgium
}

\section{A R T I C L E I N F O}

Article history:

Received 22 October 2013

Revised 28 January 2014

Accepted 10 February 2014

Available online $\mathrm{xxxx}$

\section{Keywords:}

Protein-protein interaction

Strand-transfer

Docking studies

Synthesis

\begin{abstract}
A B S T R A C T
Therapeutic treatment of AIDS is recently characterized by a crescent effort towards the identification of multiple ligands able to target different steps of HIV-1 life cycle. Taking into consideration our previously obtained SAR information and combining some important chemical structural features we report herein the synthesis of novel benzyl-indole derivatives as anti-HIV agents. Through this work we identified new dual target small molecules able to inhibit both IN-LEDGF/p75 interaction and the IN strand-transfer step considered as two crucial phases of viral life cycle.
\end{abstract}

(c) 2014 Elsevier Ltd. All rights reserved.

\section{Introduction}

Although three decades of research against the human immunodeficiency virus type 1 (HIV-1), acquired immunodeficiency syndrome (AIDS) pandemic and AIDS-related diseases remain among the leading causes of deaths worldwide. The latest UNAIDS report for the end of 2012 indicates that over 34 million individuals are living with HIV and 2.5 million new infections occur every years. ${ }^{1}$

The current combination antiretroviral therapy (cART), based on advances in the understanding of the viral life cycle, has resulted in major advances in the longevity and quality of life for infected patients, improving the clinical outcome of the disease and transforming AIDS from a rapid and lethal infection into a manageable chronic condition. ${ }^{2-4}$

However, the era of cART is not without problems: the emergence of drug-resistant viral strains, persistent toxicities, the poor ability of patients to adhere to the prescribed therapy and costs make desirable to identify additional medications targeting simultaneously different steps in the HIV-1 viral life cycle. ${ }^{5,6}$

It has been reported that HIV-1 requires three main steps for effective viral replication: reverse transcription of the RNA viral genome into viral cDNA by viral reverse transcriptase (RT); integration of viral cDNA into the host cell genome using viral integrase (IN); and, finally, cleavage of newly synthesized viral

\footnotetext{
* Corresponding author. Tel.: +39 0906766453; fax: +39 0906766402.

E-mail address: sferro@unime.it (S. Ferro).
}

polypeptides by viral protease into single viral proteins during new virion assembly. ${ }^{7}$

Throughout the years, all these steps were approached, and specific inhibitory molecules were developed and licensed to block viral enzymes, thus preventing disease progression. Only in the last decade the viral IN has emerged as a primary alternative target to block HIV-1 replication. This enzyme is critical for retroviral replication and is particularly interesting because no homolog is present in human cells. IN performs three functions that lead to viral integration into the host cell genome. The first is site-specific endonucleolytic cleavage of the $3^{\prime}$-ends of the viral DNA $\left(3^{\prime} \mathrm{P}\right)$. Secondly, it participates in the assembly of the pre-integration complex (PIC) on the ends of the viral DNA, which migrates into the host nucleus. Lastly, in the strand-transfer step (ST) IN catalyses the insertion of the viral DNA into host chromosomal DNA.

Figure 1 are shows some first generation integrase strand-transfer inhibitors (INSTIs).

At the end of 2007 the first INSTI, raltegravir, clinically effective against viruses resistant to other classes of antiretroviral agents, was approved for the clinical use by the US Food and Drug Administration (FDA) and European Medicines Agency (EMA). ${ }^{8}$

Neverthless, raltegravir has a relatively low genetic barrier to resistance $^{9,10}$ and, in contrast to prior predictions based on in vitro experiments, resistance evolves readily in the clinic. ${ }^{11}$

Elvitegravir ${ }^{12,13}$ is another first generation IN inhibitor, characterized by virologic activity comparable with raltegravir, and administered once daily combined with a pharmacological booster. 
<smiles>Cc1nnc(C(=O)NC(C)(C)c2nc(C(=O)NCc3ccc(F)cc3)c(O)c(=O)n2C)o1</smiles>

raltegravir<smiles>COc1cc2c(cc1Cc1cccc(Cl)c1F)c(=O)c(C(=O)O)cn2C(CO)C(C)C</smiles>

elvitegravir<smiles>CC1CCOC2Cn3cc(C(=O)NCc4ccc(F)cc4F)c(=O)c(O)c3C(=O)N12</smiles>

Figure 1. First and second generation of integrase strand-transfer inibitors (INSTIs).

Unfortunately, it is also cross-resistant with raltegravir and therefore it is no treatment option for patients failing on INSTIs.

The need to overcome these problems has driven the development of a second generation of INSTIs such as dolutegravir (Fig. 1) approved on August 2013. ${ }^{14}$

As the first-generation integrase inhibitors, dolutegravir blocks the strand-transfer step of integration of the viral cDNA into the host genome. It displays superior characteristics to raltegravir, but partially it shares the resistance pathways. ${ }^{15,16}$

Therefore, alternative strategies and new targets, such as the design of inhibitors of the interactions of IN with essential cellular co-factors of integration, need to be identified to combat the growing AIDS pandemic.

The ubiquitous lens epithelium growth factor LEDGF/p75 is a cellular cofactor of IN HIV-1, acting to tether the provirus to the cellular genome and playing a crucial role in the transcriptional regulation. It was demonstrated that IN-LEDGF/p75 interaction inhibitors (LEDGINs) are active against a wide range of INSTIsresistant mutants and exhibit additive or synergistic activity when combined with INSTIs. ${ }^{17}$

Our previous studies led to the discovery of small molecule protein-protein interaction inhibitors (SMPPIIs), belonging to the
CHIBA series of indoles. They proved to inhibit the interaction between IN and LEDGF/p75, ${ }^{18,19}$ and CHIBA-3053 was the most active compound (Fig. 2) ${ }^{19}$ of the series.

More recently, we found that one of the most promising indoles developed as INSTIs (CHI-1043) showed also to be active against the IN-LEDGF/p75 interaction at micromolar concentration ${ }^{20}$ (Fig. 2).

As a continuation of our research studies in this field we designed novel small molecules, containing the same scaffold of CHI$\mathrm{BA}$ and $\mathrm{CHI}$ analogues as potential inhibitors for the catalytic site of IN as well as the LEDGF/p75-IN interaction. Herein, we report the synthesis and the biological activity of this series of compounds, in which further exploration with hydrophobic groups at N1 was performed. The most active derivatives were subjected to molecular docking studies in order to analyse the binding mode of these new dual inhibitors.

\section{Results and discussion}

\subsection{Design of new analogues}

LEDGF/p75 is a cellular cofactor of HIV-1 integrase that interacts with the enzyme via its C-terminal domain, also known as the IN binding domain $\left(\mathrm{LEDGF}_{\mathrm{IBD}}\right)$ and promotes viral integration by tethering the preintegration complex to the chromatin.

Several literature data support the notion that the LEDGF/p75IN interaction is a promising target for anti-HIV drug development. ${ }^{21-24}$ Searching for HIV-1 inhibitors targeting protein-protein interactions in our previous studies we reported the discovery of a series of benzylindole derivatives able to block the IN-LEDGF/p75 interaction. The most potent compound was the 4-[1-(3,5-dimethylbenzyl)-4-hydroxy-1H-indol-3-yl]-2-hydroxy-4-oxobut-2-enoic acid (CHIBA-3053), which showed an $\mathrm{IC}_{50}$ value of $3.5 \mu \mathrm{M}$ (Fig. 2).

Moreover, considering that targeting different stages in the integration phase represents a new attractive approach for future inhibitor design, ${ }^{25-28}$ we focused our efforts towards the discovery of new molecules with potential dual site binding ability.

Our goal was to identify small molecules able to inhibit both the IN strand-transfer step and IN-LEDGF/p75 interaction.
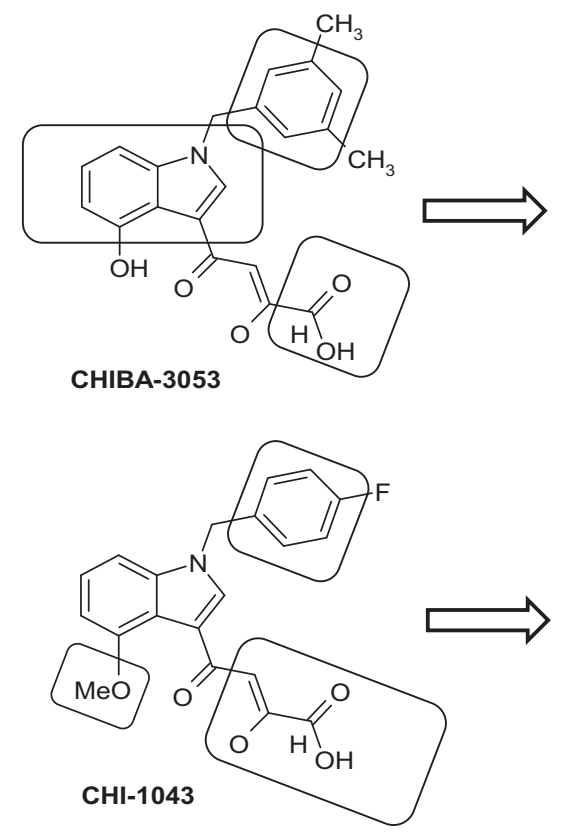

Protein-Protein Interaction Inhibitor

Strand Transfer Inhibitor and

Protein-Protein Interaction Inhibitor

Figure 2. Chemical structure of CHIBA-3053 and CHI-1043 and their major structural determinants for PPI and ST inhibition, respectively. 
As a result of these preliminary studies, derivative CHI-1043 (Fig. 2), considered the most promising compound of our INSTIs $\left(\mathrm{IC}_{50}=0.14 \mu \mathrm{M} ; \mathrm{EC}_{50}=0.59 \mu \mathrm{M} ; \mathrm{SI}=70\right)$, proved to be able to inhibit the IN-LEDGF/p75 interaction with an $\mathrm{IC}_{50}$ value of $36.16 \mu \mathrm{M}$, representing an interesting prototype of dual target agent. ${ }^{20}$

So, encouraged by these results and taking into consideration the information already obtained by our previous researches we decided to synthesize a new series of dual small molecules, combining the chemical structural features of CHIBA and CHI analogues (Fig. 2).

\subsection{Chemistry}

Scheme 1 illustrates the general synthetic route for the preparation of a new series of $1 H$-benzyl indole derivatives (13-18 $\mathbf{a}-\mathbf{f})$. By standard synthetic chemistry, ${ }^{19,29-31}$ the indole scaffold was easily equipped with a functional chain at the $\mathrm{C} 3$ position and the introduction of the benzyl moiety at N1, thus probing several substitutions for rapid exploration of the SAR profile. The $\mathrm{C} 3$ position of the indole nucleus was functionalized through the Vilsmeier-Haack reaction (4-6). Then various aryl groups were attached to the N1 atom using dry sodium hydride and the suitable benzyl bromide, and the obtained intermediates 7-9 a-f were reacted with diethyl oxalate to provide the key ethyl ester precursors (10-12 a-f) of desired compounds. Finally, the esters were hydrolyzed in basic medium to give the final diketo acids (13-15 a-f), or converted into the corresponding hydroxyl-furanones derivatives (16-18 a-f) by treatment with an aqueous solution of formaldehyde.

\subsection{AlphaScreen assay for IN-LEDGF/p75 interaction inhibition}

We tested all the new synthesized compounds in the AlphaScreen assay to evaluate their inhibitory effects on the LEDGF/ p75-IN interaction. The biological screening has been carried out on the diketo acids 13-15 a-f as well as on the hydroxyl-furanone 16-18 a-f derivatives.

The obtained results are shown in Tables 1 and 2 .

Among the compounds belonging to the diketo acid series (Table 1) the best results were displayed for compounds $\mathbf{1 3 b}, \mathbf{1 3 c}$ and $14 \mathbf{b}\left(\mathrm{IC}_{50}=22.9,9.99\right.$ and $\left.9.76 \mu \mathrm{M}\right)$. All of them were characterized by the presence of a halogen atom $(\mathrm{Cl}$ for $\mathbf{1 3 b}$ and $\mathbf{1 3 c}, \mathrm{F}$ for $14 \mathbf{b}$ ) at 5 position of the indole nucleus and of some bulky hydrophobic substituents on the benzyl moiety: 4-trifluoromethyl (13b and 14b) and 4-tert-butyl (13c) group, thus confirming our already reported studies. ${ }^{19}$

In fact, we have previously identified a new hydrophobic region in IBD binding site and demonstrated the importance of lipophilic chemical features for IN-LEDGF inhibition. Better biological results in the Alpha screen assay were obtained when the diketo acid chain has been turned into the hydroxyl-furanone cycle (Table 2). For this series (16-18 a-f) the synthesized compounds generally showed PPI inhibition at micromolar concentration thus highlighting that the structural modification of diketoacid motif in hydroxyl-furanone is well tolerated for the inhibition of the IN-LEDGF interaction.

Particularly compound $\mathbf{1 7 f}$, in which the presence of fluorine atom on the indole nucleus was associated to the introduction of

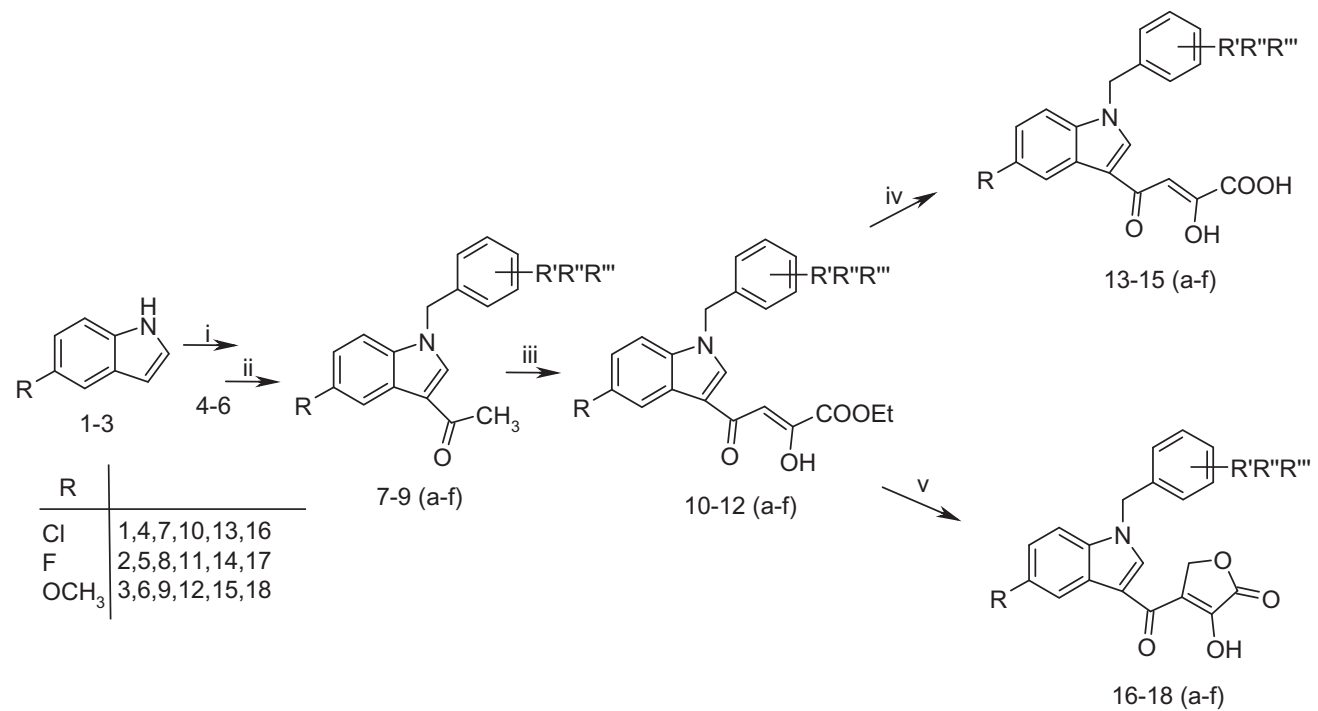

\begin{tabular}{|l|l|l|l|}
\hline & R' & R' & R'’ \\
\hline $\mathbf{a}$ & $4-\mathrm{C}_{6} \mathrm{H}_{5}$ & $\mathrm{H}$ & $\mathrm{H}$ \\
\hline $\mathbf{b}$ & $4-\mathrm{CF}_{3}$ & $\mathrm{H}$ & $\mathrm{H}$ \\
\hline $\mathbf{c}$ & $4-t \mathrm{But}$ & $\mathrm{H}$ & $\mathrm{H}$ \\
\hline $\mathbf{d}$ & $4-\mathrm{CF}_{3}$ & $2-\mathrm{CF}_{3}$ & $\mathrm{H}$ \\
\hline $\mathbf{e}$ & $\mathrm{H}$ & $3-\mathrm{CH}_{3}$ & $5-\mathrm{CH}_{3}$ \\
\hline $\mathbf{f}$ & $4-\mathrm{CH}_{3}$ & $2-\mathrm{CH}_{3}$ & $6-\mathrm{CH}_{3}$ \\
\hline
\end{tabular}

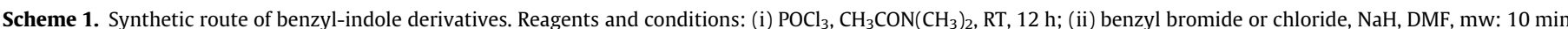

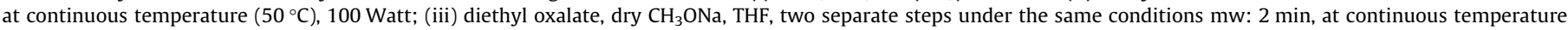
$\left(50{ }^{\circ} \mathrm{C}\right), 250$ Watt; (iv) $2 \mathrm{~N} \mathrm{NaOH}, \mathrm{MeOH}, \mathrm{RT}, 1.5 \mathrm{~h}$; (v) $\mathrm{CH}_{2} \mathrm{O}, \mathrm{Et}_{2} \mathrm{O} / \mathrm{H}_{2} \mathrm{O}, \mathrm{RT}, 2 \mathrm{~h}$. 
Table 1

Inhibition of IN-LEDGF/p75 interaction of diketo acid derivatives (13-15 a-f)

\begin{tabular}{llllll}
\hline No. & $\%^{\mathrm{a}}$ & $\mathrm{IC}_{50}{ }^{\mathrm{b}}(\mu \mathrm{M})$ & $\mathrm{No}$. & $\%^{\mathrm{a}}$ & $\mathrm{IC}_{50}{ }^{\mathrm{b}}(\mu \mathrm{M})$ \\
\hline $\mathbf{1 3 a}$ & 31 & $\mathrm{ND}^{\mathrm{d}}$ & $\mathbf{1 4 d}$ & $\mathrm{NA}$ & $\mathrm{ND}^{\mathrm{d}}$ \\
$\mathbf{1 3 b}$ & 80 & $32.9 \pm 3.5$ & $\mathbf{1 4 e}$ & 26 & $\mathrm{ND}^{\mathrm{d}}$ \\
$\mathbf{1 3 c}$ & 88 & $10.0 \pm 3.4$ & $\mathbf{1 4 f}$ & 71 & $15.2 \pm 1.6$ \\
$\mathbf{1 3 d}$ & 80 & $3.8 \pm 0.3$ & $\mathbf{1 5 a}$ & 59 & $>100$ \\
$\mathbf{1 3 e}$ & $\mathrm{NA}^{\mathrm{c}}$ & $\mathrm{ND}^{\mathrm{d}}$ & $\mathbf{1 5 b}^{32}$ & 40 & $\mathrm{ND}^{\mathrm{d}}$ \\
$\mathbf{1 3 f}$ & 59 & $>100$ & $\mathbf{1 5 c}$ & 65 & $91.7 \pm 6.2$ \\
$\mathbf{1 4 a}$ & 72 & $8.1 \pm 2.9$ & $\mathbf{1 5 d}$ & 33 & $\mathrm{ND}^{\mathrm{d}}$ \\
$\mathbf{1 4 b}$ & 77 & $17.8 \pm 7.4$ & $\mathbf{1 5 e}$ & 89 & $53.9 \pm 4.9$ \\
$\mathbf{1 4 c}$ & 33 & $\mathrm{ND}$ & $\mathbf{1 5 f}$ & 72 & $33.1 \pm 0.1$ \\
CHIBA-3053 & & 3.5 & & & \\
CHI-1043 & & 36.16 & & & \\
\hline
\end{tabular}

a $\%$ Inhibition at $100 \mu \mathrm{M}$.

b $\mathrm{IC}_{50}$ : concentration required to inhibit the HIV-1 IN-LEDGF/p75 interaction by $50 \%$. The average of two $\mathrm{IC}_{50}$ determinations and the error is shown.

c NA: not active.

d ND: not detected.

Table 2

Inhibition of IN-LEDGF/p75 interaction of hydroxyl-furanones derivatives (16-18 af)

\begin{tabular}{llllll}
\hline No. & $\%^{\mathrm{a}}$ & $\mathrm{IC}_{50}{ }^{\mathrm{b}}(\mu \mathrm{M})$ & No. & $\%^{\mathrm{a}}$ & $\mathrm{IC}_{50}{ }^{\mathrm{b}}(\mu \mathrm{M})$ \\
\hline $\mathbf{1 6 a}$ & 80 & $21.8 \pm 2.9$ & $\mathbf{1 7 d}$ & 37 & $\mathrm{ND}^{\mathrm{c}}$ \\
$\mathbf{1 6 b}$ & 92 & $12.3 \pm 1.1$ & $\mathbf{1 7 e}$ & 73 & $20.3 \pm 1.8$ \\
$\mathbf{1 6 c}$ & 83 & $52.5 \pm 1.8$ & $\mathbf{1 7 f}$ & 81 & $5.6 \pm 2.5$ \\
$\mathbf{1 6 d}$ & 86 & $21.5 \pm 0.8$ & $\mathbf{1 8 a}$ & 51 & $\mathrm{ND}^{\mathrm{c}}$ \\
$\mathbf{1 6 e}$ & 96 & $23.1 \pm 0.5$ & $\mathbf{1 8 b}$ & 65 & $52.2 \pm 9.5$ \\
$\mathbf{1 6 f}$ & 85 & $23.6 \pm 2.2$ & $\mathbf{1 8 c}$ & 93 & $17.1 \pm 2.2$ \\
$\mathbf{1 7 a}$ & 89 & $15.8 \pm 4.4$ & $\mathbf{1 8 d}$ & 61 & $39.5 \pm 6.9$ \\
$\mathbf{1 7 b}$ & 65 & $12.2 \pm 6.5$ & $\mathbf{1 8 e}$ & 66 & $\mathrm{ND}^{\mathrm{c}}$ \\
$\mathbf{1 7 c}$ & 96 & $36.2 \pm 3.4$ & $\mathbf{1 8 f}$ & 82 & $33.2 \pm 1.9$ \\
CHIBA-3053 & & 3.50 & & & \\
CHI-1043 & & 36.16 & & & \\
\hline
\end{tabular}

a $\%$ Inhibition at $100 \mu \mathrm{M}$.

b $\mathrm{IC}_{50}$ : concentration required to inhibit the HIV-1 IN-LEDGF/p75 interaction by $50 \%$. The average of two $\mathrm{IC}_{50}$ determinations and the error is shown.

c ND: not detected.

trimethyl-substitution on the benzyl moiety, showed higher potency $\left(\mathrm{IC}_{50}=2.44\right)$ than our lead compound CHIBA-3053 $\left(\mathrm{IC}_{50}=3.50\right)$.

In general, by comparison of data reported in Tables 1 and 2 the diketo acid derivatives 13-15 a-f are less active than the corresponding hydroxyl-furanones $\mathbf{1 6 - 1 8}$ a-f.

\subsection{In vitro anti-HIV and drug susceptibility assays}

All the synthesized derivatives were also tested in MT-4/MTTassay as anti-HIV agents and Table 3 shows the results for only active compounds.

The selected compounds proved to be active at micromolar concentration; generally the diketoacid derivatives (13-15) dem- onstrated better anti-HIV activity than of the closed analogues (16-18).

The better anti-HIV activity of diketoacids series respect to the hydroxyl-furanones (e.g. 17f) can be explained considering the second series of compounds as pro-drugs of the open chain DKA derivatives. $^{32}$

\subsection{Integrase strand-transfer inhibition}

On the basis of the above reported results and taking into account that one of our objectives was to identify small molecules able to simultaneously inhibit two different integration processes, we focused our attention only on those diketoacids active as antiHIV agents for evaluating their potential activity also on the strand-transfer step of IN HIV-1 integration. Thus derivatives 13b, 14b, 14f, 15e and 15f (Table 3) were selected and tested in in vitro integration assays. The obtained results are reported in Table 4.

As expected, all five derivatives showed relevant activity in the strand-transfer step at very low micromolar range. Indeed our previous SAR findings and molecular modeling studies on benzylindole diketo acids had suggested that the diketo acid portion furnishes the triad oxygen lone-pairs to serve as chelating center of the two divalent metals and that the 4-substituted benzyl group provided the appropriate spatial relationship for the aromatic moiety required for the inhibition of the integration strand-transfer event. In particular compound $\mathbf{1 4 b}$ has an $\mathrm{IC}_{50}$ in the low micromolar range for both IN-LEDGF/p75 interaction inhibition and strand transfer step.

\subsection{Docking studies}

Using Gold software and according to our previously applied protocols ${ }^{20,33,34}$ we carried out docking experiments of the most active compounds, in order to clarify their interaction with the LEDGF binding site and the catalytic site on IN. Docking results for the most promising dual inhibitor $\mathbf{1 4 b}$ are shown in Figure 3.

As regards the docking pose of $\mathbf{1 4 b}$ into the LEDGF binding site (Fig. 3A), the key interactions include hydrogen bonds between the

Table 4

Inhibition of HIV-1 integrase strand-transfer activity of diketo acid derivatives

\begin{tabular}{ll}
\hline No. & Strand-transfer ${ }^{\mathrm{a}}(\mu \mathrm{M})$ \\
\hline 13b & $0.26 \pm 0.01$ \\
$\mathbf{1 4 b}$ & $1.55 \pm 0.24$ \\
$\mathbf{1 4 f}$ & $2.51 \pm 0.56$ \\
$\mathbf{1 5 e}$ & $1.09 \pm 0.15$ \\
$\mathbf{1 5 f}$ & $0.42 \pm 0.15$ \\
CHI-1043 & $0.14 \pm 0.11$ \\
\hline
\end{tabular}

a Concentration required to inhibit by $50 \%$ the in vitro integrase activity assays as $\mathrm{IC}_{50}(\mu \mathrm{M})$.

Table 3

Antiviral activities of diketo acid derivatives (13-15 a-f) and hydroxyl-furanones (16-18 a-f)

\begin{tabular}{|c|c|c|c|c|c|c|c|}
\hline No. & $\mathrm{EC}_{50}^{\mathrm{a}}(\mu \mathrm{M})$ & $\mathrm{CC}_{50}{ }^{\mathrm{b}}(\mu \mathrm{M})$ & $\mathrm{SI}^{\mathrm{C}}$ & No. & $\mathrm{EC}_{50}^{\mathrm{a}}(\mu \mathrm{M})$ & $\mathrm{CC}_{50}^{\mathrm{b}}(\mu \mathrm{M})$ & $\mathrm{SI}^{\mathrm{C}}$ \\
\hline 13b & $5.09 \pm 1.22$ & $23 \pm 3.54$ & 5 & $16 c$ & $23.45 \pm 2.45$ & $53 \pm 7$ & 2 \\
\hline $13 e$ & $56.15 \pm 2.80$ & $>125$ & $>2$ & $16 e$ & $16.93 \pm 3.9$ & $53.5 \pm 1.5$ & 3 \\
\hline $14 b$ & $7.83 \pm 1.56$ & $15 \pm 1.75$ & 2 & $16 f$ & $19.83 \pm 1.26$ & $40.5 \pm 4.5$ & 2 \\
\hline $14 f$ & $5.14 \pm 2.9$ & $104 \pm 53$ & 21 & $17 f$ & $48.96 \pm 6.8$ & $107 \pm 12$ & 2 \\
\hline $15 e$ & $2.24 \pm 0.78$ & $51 \pm 4.68$ & 23 & CHIBA-3053 & 4.63 & 44 & 10 \\
\hline $15 f$ & $3.23 \pm 0.64$ & $23.5 \pm 2.86$ & 8 & CHI-1043 & 0.59 & 41.1 & 70 \\
\hline
\end{tabular}

${ }^{\text {a }} \mathrm{EC}_{50}$ : effective concentration required to reduce HIV-1-induced cytopathic effect by $50 \%$ in MT-4 cells.

b $\mathrm{CC}_{50}$ : cytotoxic concentration to reduce MT- 4 cell viability by $50 \%$.

c SI: ratio $\mathrm{CC}_{50} / \mathrm{EC}_{50}$. 

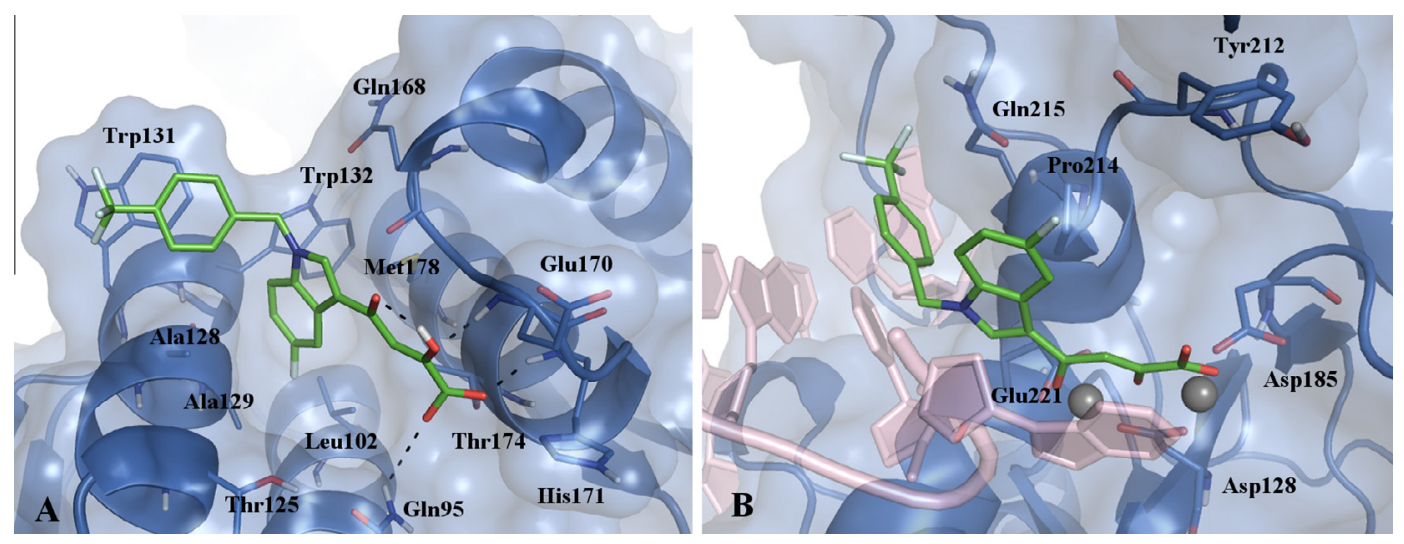

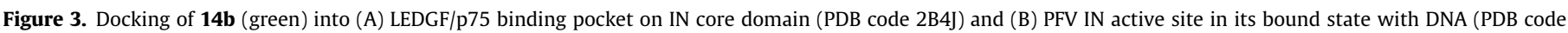
3OYA). The divalent metal ions are shown as gray spheres, while the viral DNA is depicted in pink. This figure was produced with PyMol (DeLano Scientific LLC).

diketo acid moiety and the main chain nitrogens of residues Glu170 and His171 as well as the side chain of residues Thr174 and Gln95. The $N$-benzyl substituent displays hydrophobic contacts for the crucial Trp131, while the fused benzene ring of the indole nucleus projects into the IN hydrophobic pocket with the fluorine atom forming interactions with residue Leu102 and Ala129 side chains.

The binding mode at the catalytic site during the strand-transfer step was predicted by docking $\mathbf{1 4 b}$ on the structure of integrase from PFV in complex with DNA and two $\mathrm{Mg}$ ions as previously reported for $\mathrm{CHI}-1043$ (Fig. 3B). The diketo acid moiety represents the common metal-coordinating pharmacophore of INSTIs, and the 5 -F indole group contacts Pro214, while the p-substituted benzyl moiety (that represents the second conserved feature in the INSTIs) interacts with viral DNA bases and residue Gln215.

In summary docking studies provide insights into the binding mode of $\mathbf{1 4 b}$ to form the relevant key interactions in both sites on IN.

\section{Conclusion}

In conclusion we obtained novel anti-HIV agents some of which are dual inhibitors of the integration process acting both in the IN strand-transfer step and by disrupting the protein-protein interaction between IN and its cofactor LEDGF/p75. Our approach was based on molecular modification of the indole $\beta$-diketo acid scaffold present in some inhibitors of IN-LEDGF interaction and described as an important pharmacophoric feature for INSTIs.

\section{Experimental section}

\subsection{Chemistry}

All commercially available reagents and solvents were used without any further purification. The microwave-assisted reactions were carried out in a CEM Focused Microwave Synthesis System, Model Discover, working at the power necessary for refluxing under atmospheric conditions. Melting points were determined on a BUCHI Melting Point B-545 apparatus and are uncorrected. Elemental analyses ( $\mathrm{C}, \mathrm{H}$ and $\mathrm{N}$ ) were carried out on a Carlo Erba Model 1106 Elemental Analyzer and the results are within $\pm 0.4 \%$ of the theoretical values. Merck silica gel $60 \mathrm{~F}_{254}$ plates were used for analytical TLC; column chromatography was performed on Merck silica gel 60 (230-400 mesh) and Flash Chromatography (FC) on a Biotage $\mathrm{SP}_{1}$ EXP. ${ }^{1} \mathrm{H}$ NMR spectra were recorded in $\mathrm{CDCl}_{3}$ with TMS as internal standard or $\left[D_{6}\right]$ DMSO on a Varian Gemini-300 spectrometer. Chemical shifts were expressed in $\delta$ (ppm) and coupling constants $(J)$ in hertz $(\mathrm{Hz})$. All the exchangeable protons were confirmed by addition of $\mathrm{D}_{2} \mathrm{O}$.

\subsection{Synthesis of 3-acetyl-1H-indoles (4-6)}

Synthesis of intermediates 4-6 was carried out following the previously reported procedure. Phosphoryl chloride $(0.92 \mathrm{ml}$, $10 \mathrm{mmol})$ was added to ice cold dimethylacetamide $(2.79 \mathrm{ml}$, $30 \mathrm{mmol}$ ) under stirring and cooling in ice. The suitable starting material (1-3) (1 mmol) was added and the reaction mixture was stirred at room temperature for $12 \mathrm{~h}$, then poured over ice and basified with $4 \mathrm{~N}$ aqueous sodium hydroxide solution. The mixture was extracted with ethyl acetate and dried over $\mathrm{Na}_{2} \mathrm{SO}_{4}$. After removal of the solvent under reduced pressure, the residue was powdered by treatment with diethyl ether and recrystallized from dichloromethane.

\subsubsection{3-Acetyl-5-chloro-1H-indole (4)}

Spectral data are in accordance with the literature. ${ }^{32,35}$

\subsubsection{3-Acetyl-5-fluoro-1H-indole (5)}

Mp 202-204 ${ }^{\circ} \mathrm{C}$, yield $46 \% ;{ }^{1} \mathrm{H}$ NMR (DMSO- $d_{6}$ ): 2.43 (s, 3H, $\left.\mathrm{CH}_{3}\right), 7.05-7.84(\mathrm{~m}, 3 \mathrm{H}, \mathrm{ArH}), 8.36(\mathrm{~s}, 1 \mathrm{H}, \mathrm{ArH}), 12.02(\mathrm{br} s, 1 \mathrm{H}$, $\mathrm{NH}$ ). Anal. Calcd for $\mathrm{C}_{10} \mathrm{H}_{8} \mathrm{FNO}$ : C, 67.79; $\mathrm{H}, 4.55 ; \mathrm{N}, 7.91$. Found: C, 67.94; H, 4.31; N, 7.72.

\subsubsection{3-Acetyl-5-methoxy- $1 H$-indole (6)}

Spectral data are in accordance with the literature. ${ }^{32,35}$

\subsection{General procedure for the synthesis of 3-acetyl-1-benzyl- $1 \mathrm{H}$-indoles (7-9 a-f)}

Using the synthetic procedure previously reported by us ${ }^{18-}$ 20,29,36 3 -acetyl- 1 H-indole derivatives 4-6 were dissolved in DMF $(2 \mathrm{ml})$ at $0{ }^{\circ} \mathrm{C}$ and dry sodium hydride $(120 \mathrm{mg}, 5 \mathrm{mmol})$ was added. After stirring for $2 \mathrm{~min}$, the suitable benzyl bromide or chloride $(1.5 \mathrm{mmol})$ was added in several portions. The resulting solution was placed in a cylindrical quartz tube (diam. $2 \mathrm{~cm}$ ), stirred and irradiated in a microwave oven at $100 \mathrm{~W}$ and at continuous temperature $\left(50{ }^{\circ} \mathrm{C}\right)$ for $10 \mathrm{~min}$. A saturated $\mathrm{NaHCO}_{3}$ solution was added. The reaction mixture was extracted with ethyl acetate $(10 \mathrm{ml} \times 3)$ and dried over $\mathrm{Na}_{2} \mathrm{SO}_{4}$. After removal of the solvent under reduced pressure, the crude mixture was crystallized from diethyl ether or purified by flash chromatography using a mixture of cyclohexane/ethylacetate (60:40) as eluent. 


\subsubsection{3-Acetyl-1-(4-phenylbenzyl)-5-chloro- $1 \mathrm{H}$-indole (7a)}

Mp 154-56 ${ }^{\circ} \mathrm{C}$, yield 90\%; ${ }^{1} \mathrm{H}$ NMR $(\delta)\left(\mathrm{CDCl}_{3}\right): 2.52\left(\mathrm{~s}, 3 \mathrm{H}, \mathrm{CH}_{3}\right)$, $5.38\left(\mathrm{~s}, 2 \mathrm{H}, \mathrm{CH}_{2}\right), 7.20-7.24(\mathrm{~m}, 3 \mathrm{H}, \mathrm{ArH}), 7.36-7.47$ (m, 4H, ArH), 7.55-7.59 (m, 4H, ArH), 7.80 (s, 1H, ArH), 8.43 (s, 1H, ArH). Anal. Calcd for $\mathrm{C}_{23} \mathrm{H}_{18} \mathrm{ClNO}$ : C: $76.77 ; \mathrm{H}$ : $5.04 ; \mathrm{N}$ : 3.89. Found: C: 76.45; H: 5.23; N: 3.68 .

\subsubsection{3-Acetyl-1-(4-trifluoromethylbenzyl)-5-chloro-1H-indole} (7b)

Mp 163-165 ${ }^{\circ} \mathrm{C}$, yield 50\%; ${ }^{1} \mathrm{H}$ NMR $\left(\mathrm{CDCl}_{3}\right): 2.52\left(\mathrm{~s}, 3 \mathrm{H}, \mathrm{CH}_{3}\right)$, $5.41\left(\mathrm{~s}, 2 \mathrm{H}, \mathrm{CH}_{2}\right), 7.12(\mathrm{~d}, J=9.1,1 \mathrm{H}, \mathrm{ArH}), 7.21-7.26(\mathrm{~m}, 3 \mathrm{H}$, $\operatorname{ArH}), 7.60(\mathrm{~d}, J=8.2,2 \mathrm{H}, \operatorname{ArH}), 7.77(\mathrm{~s}, 1 \mathrm{H}, \operatorname{ArH}), 8.43(\mathrm{~s}, 1 \mathrm{H}$, ArH). Anal. Calcd for $\mathrm{C}_{18} \mathrm{H}_{13} \mathrm{ClF}_{3} \mathrm{NO}$ : C: $61.46 ; \mathrm{H}: 3.73 ; \mathrm{N}: 3.98$. Found: C: 61.72 ; H: 3.89; N: 4.03 .

\subsubsection{3-Acetyl-1-(4-tert-butylbenzyl)-5-chloro-1H-indole (7c)}

Mp 158-160 ${ }^{\circ} \mathrm{C}$, yield 44\%; ${ }^{1} \mathrm{H}$ NMR $\left(\mathrm{CDCl}_{3}\right): 1.30\left(\mathrm{~s}, 9 \mathrm{H}, \mathrm{CH}_{3}\right)$, $2.50\left(\mathrm{~s}, 3 \mathrm{H}, \mathrm{CH}_{3}\right), 5.30$ (s, $\left.2 \mathrm{H}, \mathrm{CH}_{2}\right), 7.10$ (d, J=8.5, $\left.2 \mathrm{H}, \mathrm{ArH}\right), 7.22$ $(\mathrm{s}, 1 \mathrm{H}, \operatorname{ArH}), 7.36(\mathrm{~d}, J=8.5,2 \mathrm{H}, \operatorname{ArH}), 7.75(\mathrm{~s}, 1 \mathrm{H}, \operatorname{ArH}), 8.40(\mathrm{~s}$, $1 \mathrm{H}, \mathrm{ArH}$ ). Anal. Calcd for $\mathrm{C}_{21} \mathrm{H}_{22} \mathrm{ClNO}$ : C: 74.22; $\mathrm{H}: 6.52 ; \mathrm{N}: 4.12$. Found: C: $74.34 ; \mathrm{H}: 6.36$; N: 4.31 .

\subsubsection{3-Acetyl-1-(2,4-bis-trifluoromethylbenzyl)-5-chloro-1H-} indole (7d)

Mp 163-165 ${ }^{\circ} \mathrm{C}$, yield 35\%; ${ }^{1} \mathrm{H}$ NMR $\left(\mathrm{CDCl}_{3}\right): 2.55\left(\mathrm{~s}, 3 \mathrm{H}, \mathrm{CH}_{3}\right)$, $5.63\left(\mathrm{~s}, 2 \mathrm{H}, \mathrm{CH}_{2}\right), 6.71(\mathrm{~d}, J=7.6,1 \mathrm{H}, \operatorname{ArH}), 7.03(\mathrm{~d}, J=8.8,1 \mathrm{H}$, ArH), 7.23 (d, $J=8.8,1 \mathrm{H}, \operatorname{ArH}), 7.64(\mathrm{~d}, J=7.6,1 \mathrm{H}, \operatorname{ArH}), 7.79(\mathrm{~s}$, $1 \mathrm{H}, \mathrm{ArH}), 8.02(\mathrm{~s}, 1 \mathrm{H}, \mathrm{ArH}), 8.45(\mathrm{~s}, 1 \mathrm{H}, \mathrm{ArH})$. Anal. Calcd for $\mathrm{C}_{19} \mathrm{H}_{12-}$ $\mathrm{ClF}_{6} \mathrm{NO}$ : C: 54.37; H: 2.88; N: 3.34. Found: C: 54.55; H: 3.09; N: 3.61.

4.3.5. 3-Acetyl-1-(3,5-dimethylbenzyl)-5-chloro- $1 \mathrm{H}$-indole (7e)

Mp 136-138 ${ }^{\circ} \mathrm{C}$, yield 47\%; ${ }^{1} \mathrm{H}$ NMR $\left(\mathrm{CDCl}_{3}\right): 2.27\left(\mathrm{~s}, 3 \mathrm{H}, \mathrm{CH}_{3}\right)$, $2.50\left(\mathrm{~s}, 3 \mathrm{H}, \mathrm{CH}_{3}\right), 5.24\left(\mathrm{~s}, 2 \mathrm{H}, \mathrm{CH}_{2}\right), 6.75(\mathrm{~s}, 2 \mathrm{H}, \mathrm{ArH}), 6.95(\mathrm{~s}, 1 \mathrm{H}$, ArH), 7.19-7.22 (m, 2H, ArH), 7.74 (s, 1H, ArH), 8.40 (s, 1H, ArH). Anal. Calcd for $\mathrm{C}_{19} \mathrm{H}_{18} \mathrm{ClNO}$ : C: $73.19 ; \mathrm{H}: 5.82 ; \mathrm{N}: 4.49$. Found: C: 73.34; $\mathrm{H}: 5.71 ; \mathrm{N}: 4.56$.

\subsubsection{3-Acetyl-1-(2,4,6-trimethylbenzyl)-5-chloro-1H-indole} (7f)

Mp 193-195 ${ }^{\circ} \mathrm{C}$, yield 67\%; ${ }^{1} \mathrm{H}$ NMR $\left(\mathrm{CDCl}_{3}\right): 2.22\left(\mathrm{~s}, 6 \mathrm{H}, \mathrm{CH}_{3}\right)$, $2.35\left(\mathrm{~s}, 3 \mathrm{H}, \mathrm{CH}_{3}\right), 2.36\left(\mathrm{~s}, 3 \mathrm{H}, \mathrm{CH}_{3}\right), 5.20\left(\mathrm{~s}, 2 \mathrm{H}, \mathrm{CH}_{2}\right), 6.87(\mathrm{~s}, 1 \mathrm{H}$, $\mathrm{ArH}), 6.99(\mathrm{~s}, 2 \mathrm{H}, \mathrm{ArH}), 7.18(\mathrm{~s}, 1 \mathrm{H}, \operatorname{ArH}), 7.30(\mathrm{~d}, J=8.8,1 \mathrm{H}$, $\mathrm{ArH}), 7.43$ (d, $J=8.8,1 \mathrm{H}, \mathrm{ArH}$ ). Anal. Calcd for $\mathrm{C}_{20} \mathrm{H}_{20} \mathrm{ClNO}$ : C: 73.72; H: 6.19; N: 4.30. Found: C: 73.59; H: 6.33; N: 4.48.

\subsubsection{3-Acetyl-1-(4-phenylbenzyl)-5-fluoro-1H-indole (8a)}

Mp 81-83 ${ }^{\circ} \mathrm{C}$, yield 48\%; ${ }^{1} \mathrm{H}$ NMR $\left(\mathrm{CDCl}_{3}\right): 2.52\left(\mathrm{~s}, 3 \mathrm{H}, \mathrm{CH}_{3}\right), 5.39$ $\left(\mathrm{s}, 2 \mathrm{H}, \mathrm{CH}_{2}\right), 7.02(\mathrm{t}, J=9,1 \mathrm{H}, \mathrm{ArH}), 7.21-7.25(\mathrm{~m}, 3 \mathrm{H}, \mathrm{ArH}), 7.37(\mathrm{~d}$, $J=6.9,1 \mathrm{H}, \mathrm{ArH}), 7.44(\mathrm{t}, J=8,2 \mathrm{H}, \mathrm{ArH}), 7.55-7.62(\mathrm{~m}, 4 \mathrm{H}, \mathrm{ArH})$, $7.82(\mathrm{~s}, 1 \mathrm{H}, \mathrm{ArH}), 8.10$ (d, $J=9.6,1 \mathrm{H}, \mathrm{ArH})$. Anal. Calcd for $\mathrm{C}_{23} \mathrm{H}_{18-}$ FNO: C: 80.45 ; H: 5.28: N, 4.08. Found: C: 80.21 ; H: 5.45; N: 4.24.

\subsubsection{3-Acetyl-1-(4-trifluoromethylbenzyl)-5-fluoro-1H-indole} (8b)

Mp 185-187 ${ }^{\circ} \mathrm{C}$, yield $62 \% ;{ }^{1} \mathrm{H}$ NMR $\left(\mathrm{CDCl}_{3}\right): 2.53\left(\mathrm{~s}, 3 \mathrm{H}, \mathrm{CH}_{3}\right)$, $5.42\left(\mathrm{~s}, 2 \mathrm{H}, \mathrm{CH}_{2}\right), 7.01(\mathrm{t}, J=9,1 \mathrm{H}, \operatorname{ArH}), 7.13(\mathrm{~d}, J=9,1 \mathrm{H}, \mathrm{ArH})$, $7.23(\mathrm{~d}, J=7.9,2 \mathrm{H}, \operatorname{ArH}), 7.60(\mathrm{~d}, J=8.2,2 \mathrm{H}, \operatorname{ArH}), 7.80(\mathrm{~s}, 1 \mathrm{H}$, $\mathrm{ArH}), 8.10$ (d, $J=9.5,1 \mathrm{H}, \mathrm{ArH})$. Anal. Calcd for $\mathrm{C}_{18} \mathrm{H}_{13} \mathrm{~F}_{4} \mathrm{NO}$ : C: 64.48; H: 3.91; N: 4.18. Found: C: 64.32; H: 3.74; N: 4.29 .

\subsubsection{3-Acetyl-1-(4-tert-butylbenzyl)-5-fluoro- $1 \mathrm{H}$-indole $(8 \mathrm{c})$}

Mp 132-134 ${ }^{\circ} \mathrm{C}$, yield 50\%; ${ }^{1} \mathrm{H}$ NMR $\left(\mathrm{CDCl}_{3}\right): 1.32\left(\mathrm{~s}, 9 \mathrm{H}, \mathrm{CH}_{3}\right)$, $2.52\left(\mathrm{~s}, 3 \mathrm{H}, \mathrm{CH}_{3}\right), 5.33\left(\mathrm{~s}, 2 \mathrm{H}, \mathrm{CH}_{2}\right), 7.02(\mathrm{t}, J=8.8,1 \mathrm{H}, \mathrm{ArH}), 7.11$ $(\mathrm{d}, J=8.8,2 \mathrm{H}, \mathrm{ArH}), 7.23-7.28(\mathrm{~m}, 1 \mathrm{H}, \mathrm{ArH}), 7.39(\mathrm{~d}, J=8.8,2 \mathrm{H}$, $\operatorname{ArH}), 7.79(\mathrm{~s}, 1 \mathrm{H}, \mathrm{ArH}), 8.09(\mathrm{~d}, J=9.9,1 \mathrm{H}, \mathrm{ArH})$. Anal. Calcd for $\mathrm{C}_{21}$ -
$\mathrm{H}_{22}$ FNO: C: 77.99; H: 6.86; N: 4.33. Found: C: 78.13; $\mathrm{H}: 6.99 ; \mathrm{N}$ : 4.22 .

4.3.10. 3-Acetyl-1-(2,4-bis-trifluoromethylbenzyl)-5-fluoro-1Hindole (8d)

Mp 144-146 ${ }^{\circ} \mathrm{C}$, yield 35\%; ${ }^{1} \mathrm{H}$ NMR $\left(\mathrm{CDCl}_{3}\right): 2.55$ (s, 3H, $\left.\mathrm{CH}_{3}\right)$, $5.63\left(\mathrm{~s}, 2 \mathrm{H}, \mathrm{CH}_{2}\right), 6.73(\mathrm{~d}, J=8.2,1 \mathrm{H}, \mathrm{ArH}), 7.03(\mathrm{~d}, J=8.2,2 \mathrm{H}$ $\operatorname{ArH}), 7.65(\mathrm{~d}, J=8.2,1 \mathrm{H}, \operatorname{ArH}), 7.82(\mathrm{~s}, 1 \mathrm{H}, \operatorname{ArH}), 8.02(\mathrm{~s}, 1 \mathrm{H}$, ArH), $8.13(\mathrm{~d}, J=9.2,1 \mathrm{H}, \mathrm{ArH})$. Anal. Calcd for $\mathrm{C}_{19} \mathrm{H}_{12} \mathrm{~F}_{7} \mathrm{NO}$ : C: 58.92; H: 3.12; N: 3.62. Found: C: 59.21; H: 3.45; N: 3.96.

4.3.11. 3-Acetyl-1-(3,5-dimethylbenzyl)-5-fluoro- $1 H$-indole (8e)

Mp 146-148 ${ }^{\circ} \mathrm{C}$, yield 57\%; ${ }^{1} \mathrm{H}$ NMR $\left(\mathrm{CDCl}_{3}\right): 2.28\left(\mathrm{~s}, 6 \mathrm{H}, \mathrm{CH}_{3}\right)$, $2.51\left(\mathrm{~s}, 3 \mathrm{H}, \mathrm{CH}_{3}\right), 5.25\left(\mathrm{~s}, 2 \mathrm{H}, \mathrm{CH}_{2}\right), 6.76(\mathrm{~s}, 2 \mathrm{H}, \mathrm{ArH}), 6.96-7.02$ (m, 2H, ArH), 7.20-7.24 (m, 1H, ArH), 7.76 (s, 1H, ArH), 8.08 (d, $J=7.4,1 \mathrm{H}, \mathrm{ArH}$ ). Anal. Calcd for $\mathrm{C}_{19} \mathrm{H}_{18} \mathrm{FNO}$ : C: 77.27 ; $\mathrm{H}: 6.14$; N: 4.74. Found: C: 77.39; $\mathrm{H}: 6.28$; N: 4.81.

\subsubsection{3-Acetyl-1-(2,4,6-trimethylbenzyl)-5-fluoro-1H-indole} (8f)

Mp 135-137 ${ }^{\circ} \mathrm{C}$, yield 42\%; ${ }^{1} \mathrm{H}$ NMR $\left(\mathrm{CDCl}_{3}\right): 2.23\left(\mathrm{~s}, 6 \mathrm{H}, \mathrm{CH}_{3}\right)$, $2.36\left(\mathrm{~s}, 6 \mathrm{H}, \mathrm{CH}_{3}\right), 5.21\left(\mathrm{~s}, 2 \mathrm{H}, \mathrm{CH}_{2}\right), 6.88(\mathrm{~s}, 1 \mathrm{H}, \mathrm{ArH}), 6.99(\mathrm{~s}, 1 \mathrm{H}$, $\operatorname{ArH}), 7.10$ (t, $J=8.8,1 \mathrm{H}, \operatorname{ArH}), 7.19$ (s, 1H, ArH), 7.43 (d, $J=8.8$, $1 \mathrm{H}, \mathrm{ArH}), 8.07(\mathrm{~d}, J=9.6,1 \mathrm{H}, \mathrm{ArH})$. Anal. Calcd for $\mathrm{C}_{20} \mathrm{H}_{20} \mathrm{FNO}$ : C: 77.64; H: 6.52; N: 4.53. Found: C: 77.87; H: 6.68; N: 4.31.

\subsubsection{3-Acetyl-1-(4-phenylbenzyl)-5-methoxy-1H-indole (9a)}

Mp 154-156 ${ }^{\circ} \mathrm{C}$, yield 90\%; ${ }^{1} \mathrm{H}$ NMR $\left(\mathrm{CDCl}_{3}\right): 2.52\left(\mathrm{~s}, 3 \mathrm{H}, \mathrm{CH}_{3}\right)$, $3.91\left(\mathrm{~s}, 3 \mathrm{H}, \mathrm{OCH}_{3}\right), 5.37\left(\mathrm{~s}, 2 \mathrm{H}, \mathrm{CH}_{2}\right), 6.91(\mathrm{~d}, J=8.8,1 \mathrm{H}, \mathrm{ArH})$, 7.20-7.24 (m, 3H, ArH), 7.37 (d, $J=7.2,1 \mathrm{H}, \operatorname{ArH}) 7.44(\mathrm{t}, J=8.8$, 2H, ArH), 7.55-7.58 (m, 4H, ArH), $7.76(\mathrm{~s}, 1 \mathrm{H}, \mathrm{ArH}), 7.94(\mathrm{~s}, 1 \mathrm{H}$, ArH). Anal. Calcd for $\mathrm{C}_{24} \mathrm{H}_{21} \mathrm{NO}_{2}$ : C: $81.10 ; \mathrm{H}: 5.96 ; \mathrm{N}$ : 3.94. Found: C: $81.34 ; \mathrm{H}, 5.72 ; \mathrm{N}, 4.09$.

\subsubsection{3-Acetyl-1-(4-trifluoromethylbenzyl)-5-methoxy-1H- indole (9b)}

Mp 122-124 ${ }^{\circ} \mathrm{C}$, yield 70\%; ${ }^{1} \mathrm{H}$ NMR $\left(\mathrm{CDCl}_{3}\right): 2.53\left(\mathrm{~s}, 3 \mathrm{H}, \mathrm{CH}_{3}\right)$, $3.90\left(\mathrm{~s}, 3 \mathrm{H}, \mathrm{OCH}_{3}\right), 5.40\left(\mathrm{~s}, 2 \mathrm{H}, \mathrm{CH}_{2}\right), 6.90(\mathrm{~d}, J=8.8,1 \mathrm{H}, \mathrm{ArH})$, 7.09 (d, $J=8.8,1 \mathrm{H}, \operatorname{ArH}), 7.23$ (d, $J=8,2 \mathrm{H}, \operatorname{ArH}), 7.60$ (d, $J=8.2$, $2 \mathrm{H}, \mathrm{ArH}), 7.73(\mathrm{~s}, 1 \mathrm{H}, \mathrm{ArH}), 7.93(\mathrm{~s}, 1 \mathrm{H}, \mathrm{ArH})$. Anal. Calcd for $\mathrm{C}_{19} \mathrm{H}_{16}$ $\mathrm{F}_{3} \mathrm{NO}_{2}$ : C: 65.70; H: 4.64; N: 4.03. Found: C: 65.87; H: 4.48; N: 4.21.

\subsubsection{3-Acetyl-1-(4-tert-butylbenzyl)-5-methoxy-1H-indole (9c)}

Mp 149-151 ${ }^{\circ} \mathrm{C}$, yield 73\%; ${ }^{1} \mathrm{H}$ NMR $\left(\mathrm{CDCl}_{3}\right)$ : $1.29\left(\mathrm{~s}, 9 \mathrm{H}, \mathrm{CH}_{3}\right)$, $2.68\left(\mathrm{~s}, 3 \mathrm{H}, \mathrm{CH}_{3}\right), 3.97\left(\mathrm{~s}, 3 \mathrm{H}, \mathrm{OCH}_{3}\right), 5.25\left(\mathrm{~s}, 2 \mathrm{H}, \mathrm{CH}_{2}\right), 6.69(\mathrm{~d}$, $J=7.9,1 \mathrm{H}, \operatorname{ArH}), 6.96(\mathrm{~d}, J=7.9,1 \mathrm{H}, \operatorname{ArH}), 7.09(\mathrm{~d}, J=8.5,2 \mathrm{H}$, ArH), 7.17 (d, $J=7.9,1 \mathrm{H}, \operatorname{ArH}), 7.34$ (d, $J=8.5,2 \mathrm{H}, \operatorname{ArH}), 7.72(\mathrm{~s}$, $1 \mathrm{H}, \mathrm{ArH})$. Anal. Calcd for $\mathrm{C}_{22} \mathrm{H}_{25} \mathrm{NO}_{2}$ : C: 78.77; $\mathrm{H}: 7.51 ; \mathrm{N}: 4.18$. Found: C: 78.95; H: 7.74; N: 4.51 .

\subsubsection{3-Acetyl-1-(2,4-bis-trifluoromethylbenzyl)-5-methoxy- $1 \mathrm{H}$-indole (9d)}

Mp 158-160 ${ }^{\circ} \mathrm{C}$, yield 37\%; ${ }^{1} \mathrm{H}$ NMR (DMSO- $d_{6}$ ): $2.49(\mathrm{~s}, 3 \mathrm{H}$, $\left.\mathrm{CH}_{3}\right), 3.80\left(\mathrm{~s}, 3 \mathrm{H}, \mathrm{OCH}_{3}\right), 5.80\left(\mathrm{~s}, 2 \mathrm{H}, \mathrm{CH}_{2}\right), 6.80(\mathrm{~d}, J=8.4,1 \mathrm{H}$ $\operatorname{ArH}), 6.92(\mathrm{~s}, 2 \mathrm{H}, \operatorname{ArH}), 7.25(\mathrm{~d}, J=8.8,2 \mathrm{H}, \operatorname{ArH}), 7.79(\mathrm{~s}, 1 \mathrm{H}$, $\operatorname{ArH}), 7.95(\mathrm{~d}, J=8.4,1 \mathrm{H}, \operatorname{ArH}), 8.13(\mathrm{~s}, 1 \mathrm{H}, \operatorname{ArH}), 8.86(\mathrm{~s}, 1 \mathrm{H}$, ArH). Anal. Calcd for $\mathrm{C}_{20} \mathrm{H}_{15} \mathrm{~F}_{6} \mathrm{NO}_{2}$ : C: $57.84 ; \mathrm{H}: 3.64 ; \mathrm{N}: 3.37$. Found: C: 57.70 ; H: 3.81 ; N: 3.52 .

\subsubsection{3-Acetyl-1-(3,5-dimethylbenzyl)-5-methoxy-1H-indole (9e)}

Mp $130-132{ }^{\circ} \mathrm{C}$, yield 59\%; ${ }^{1} \mathrm{H}$ NMR $\left(\mathrm{CDCl}_{3}\right): 2.27\left(\mathrm{~s}, 6 \mathrm{H}, \mathrm{CH}_{3}\right)$, $2.50\left(\mathrm{~s}, 3 \mathrm{H}, \mathrm{CH}_{3}\right), 3.90\left(\mathrm{~s}, 3 \mathrm{H}, \mathrm{OCH}_{3}\right), 5.22\left(\mathrm{~s}, 2 \mathrm{H}, \mathrm{CH}_{2}\right), 6.77(\mathrm{~s}$, $2 \mathrm{H}, \mathrm{ArH}), 6.91(\mathrm{t}, J=8.8,2 \mathrm{H}, \mathrm{ArH}), 7.19(\mathrm{~d}, J=8.8,1 \mathrm{H}, \mathrm{ArH}), 7.69$ 
(s, $1 \mathrm{H}, \mathrm{ArH}), 7.92(\mathrm{~s}, 1 \mathrm{H}, \mathrm{ArH})$. Anal. Calcd for $\mathrm{C}_{20} \mathrm{H}_{21} \mathrm{NO}_{2}$ : C: 78.15; H: 6.89; N: 4.56. Found: C: 78.36; H: 6.72; N: 4.68 .

\subsubsection{3-Acetyl-1-(2,4,6-trimethylbenzyl)-5-methoxy-1H-} indole (9f)

Mp 150-152 ${ }^{\circ} \mathrm{C}$, yield 28\%; ${ }^{1} \mathrm{H}$ NMR $\left(\mathrm{CDCl}_{3}\right): 2.23\left(\mathrm{~s}, 6 \mathrm{H}, \mathrm{CH}_{3}\right)$, $2.35\left(\mathrm{~s}, 6 \mathrm{H}, \mathrm{CH}_{3}\right), 3.91\left(\mathrm{~s}, 3 \mathrm{H}, \mathrm{OCH}_{3}\right), 5.19\left(\mathrm{~s}, 2 \mathrm{H}, \mathrm{CH}_{2}\right), 6.97-7.01$ (m, 2H, ArH), $7.12(\mathrm{~s}, 1 \mathrm{H}, \mathrm{ArH}), 7.40$ (d, $J=8.5,2 \mathrm{H}, \operatorname{ArH}), 7.92(\mathrm{~s}$, $1 \mathrm{H}, \mathrm{ArH}$ ). Anal. Calcd for $\mathrm{C}_{21} \mathrm{H}_{23} \mathrm{NO}_{2}$ : C: 78.47; $\mathrm{H}: 7.21 ; \mathrm{N}: 4.36$. Found: C: 78.69; H: 7.04; N: 4.54.

4.4. General procedure for the synthesis of ethyl 4-[1-benzyl1H-indol-3-yl]-2-hydroxy-4-oxobut-2-enoates (10-12 a-f)

Intermediates 10-12 a-f were obtained adopting the synthetic procedure previously reported by us. ${ }^{18,19,31,32}$ A mixture of suitable 3-acetyl-1-benzyl-1H-indole (7-9 a-f) (1 mmol) diethyl oxalate (219 mg, $1.5 \mathrm{mmol}$ ) and a catalytic amount of $\mathrm{NaOCH}_{3}$ was suspended in anhydrous THF $(2 \mathrm{ml})$. The reaction mixture was placed in a cylindrical quartz tube (diam. $2 \mathrm{~cm}$ ), stirred and irradiated at continuous temperature in a microwave oven for two successive time intervals under the same conditions (250 Watt, 2 min, $50{ }^{\circ} \mathrm{C}$ ). The solvent was concentrated under reduced pressure and collected yellow solid was crystallized from ethanol and diethyl ether (1:4).

\subsubsection{Ethyl 4-[1-(4-phenylbenzyl)-5-chloro-1H-indol-3-yl]-2-} hydroxy-4-oxobut-2-enoate (10a)

Mp 198-200 ${ }^{\circ} \mathrm{C}$, yield 95\%; ${ }^{1} \mathrm{H}$ NMR (DMSO- $\left.d_{6}\right): 1.24(\mathrm{t}, J=7.3$, $\left.3 \mathrm{H}, \mathrm{CH}_{3}\right), 4.12\left(\mathrm{q}, J=7.3,2 \mathrm{H}, \mathrm{CH}_{2}\right), 5.50\left(\mathrm{~s}, 2 \mathrm{H}, \mathrm{CH}_{2}\right), 6.21$ (br s, $1 \mathrm{H}, \mathrm{OH}), 7.12(\mathrm{~d}, J=9,1 \mathrm{H}, \mathrm{ArH}), 7.31-7.45(\mathrm{~m}, 6 \mathrm{H}, 5 \mathrm{ArH}$ and $\mathrm{CH})$, $7.52(\mathrm{~d}, J=7.6,1 \mathrm{H}, \operatorname{ArH}), 7.58-7.61(\mathrm{~m}, 4 \mathrm{H}, \operatorname{ArH}), 8.25(\mathrm{~s}, 1 \mathrm{H}$ ArH), 8.36 (s, $1 \mathrm{H}, \mathrm{ArH}$ ). (Anal. Calcd for $\mathrm{C}_{27} \mathrm{H}_{22} \mathrm{ClNO}_{4}$ : C: $70.51 ; \mathrm{H}$ : 4.82; N: 3.05. Found: C: 70.12; H: 4.99; N: 3.24 .

4.4.2. Ethyl 4-\{1-[4-(trifluoromethyl)benzyl]-5-chloro-1Hindol-3-yl\}-2-hydroxy-4-oxobut-2-enoate (10b)

Mp 170-172 ${ }^{\circ} \mathrm{C}$, yield 75\%; ${ }^{1} \mathrm{H}$ NMR (DMSO- $\left.d_{6}\right): 1.24(\mathrm{t}, J=7.3$, $\left.3 \mathrm{H}, \mathrm{CH}_{3}\right), 3.94\left(\mathrm{q}, J=7.3,2 \mathrm{H}, \mathrm{CH}_{2}\right), 5.59\left(\mathrm{~s}, 2 \mathrm{H}, \mathrm{CH}_{2}\right), 6.35(\mathrm{~s}, 1 \mathrm{H}$, $\mathrm{OH}), 7.14(\mathrm{~d}, J=8,1 \mathrm{H}, \mathrm{ArH}), 7.42(\mathrm{~d}, J=8,2 \mathrm{H}, \mathrm{ArH}$ and $\mathrm{CH}), 7.47$ (d, $J=8.9,2 \mathrm{H}, \operatorname{ArH}), 7.68$ (d, $J=8,2 \mathrm{H}, \operatorname{ArH}), 8.38(\mathrm{~s}, 1 \mathrm{H}, \operatorname{ArH}), 8.43$ (s, $1 \mathrm{H}, \mathrm{ArH}$ ). Anal. Calcd for $\mathrm{C}_{22} \mathrm{H}_{17} \mathrm{ClF}_{3} \mathrm{NO}_{4}$ : C: $58.48 ; \mathrm{H}: 3.79 ; \mathrm{N}$ : 3.10. Found: C: $58.61 ; \mathrm{H}: 4.03 ; \mathrm{N}: 3.17$.

4.4.3. Ethyl 4-[1-(4-tert-butylbenzyl)-5-chloro-1H-indol-3-yl]-2hydroxy-4-oxobut-2-enoate (10c)

Mp $280{ }^{\circ} \mathrm{C} \mathrm{dec}$, yield 85\%; ${ }^{1} \mathrm{H}$ NMR (DMSO- $\left.d_{6}\right): 1.20\left(\mathrm{~s}, 9 \mathrm{H}, \mathrm{CH}_{3}\right)$, $1.24\left(\mathrm{t}, J=6.9,3 \mathrm{H}, \mathrm{CH}_{3}\right), 4.13\left(\mathrm{~d}, J=7.2,2 \mathrm{H}, \mathrm{CH}_{2}\right), 5.41\left(\mathrm{~s}, 2 \mathrm{H}, \mathrm{CH}_{2}\right)$, $6.16(\mathrm{~s}, 1 \mathrm{H}, \mathrm{ArH}), 7.11-7.22(\mathrm{~m}, 3 \mathrm{H}, 2 \mathrm{ArH}$ and $\mathrm{CH}), 7.33(\mathrm{~d}, J=7.7$, $2 \mathrm{H}, \operatorname{ArH}), 7.50(\mathrm{~d}, J=8.8,1 \mathrm{H}, \operatorname{ArH}), 8.17(\mathrm{~s}, 1 \mathrm{H}, \operatorname{ArH}), 8.43(\mathrm{~s}, 1 \mathrm{H}$, ArH), 8.53 (s, $1 \mathrm{H}, \mathrm{ArH})$. Anal. Calcd for $\mathrm{C}_{25} \mathrm{H}_{26} \mathrm{ClNO}_{4}$ : C: $68.25 ; \mathrm{H}$ : 5.96; N: 3.18. Found: C: 68.34; H: 6.01; N: 3.25 .

4.4.4. Ethyl 4-\{1-[2,4-bis(trifluoromethyl)benzyl]-5-chloro-1Hindol-3-yl\}-2-hydroxy-4-oxobut-2-enoate (10d)

Mp 223-225 ${ }^{\circ} \mathrm{C}$, yield 68\%; ${ }^{1} \mathrm{H}$ NMR (DMSO- $d_{6}$ ): 1.23 (t, $J=7.3$, $\left.3 \mathrm{H}, \mathrm{CH}_{3}\right), 4.10\left(\mathrm{q}, J=7.3,2 \mathrm{H}, \mathrm{CH}_{2}\right), 5.79\left(\mathrm{~s}, 2 \mathrm{H}, \mathrm{CH}_{2}\right), 6.20(\mathrm{~s}, 1 \mathrm{H}$, $\mathrm{OH}), 6.62(\mathrm{~d}, J=8.8,1 \mathrm{H}, \mathrm{ArH}), 7.11-7.23(\mathrm{~m}, 3 \mathrm{H}, 2 \mathrm{ArH}$ and $\mathrm{CH})$, $7.94(\mathrm{~d}, J=8.5,1 \mathrm{H}, \operatorname{ArH}), 8.11(\mathrm{~s}, 1 \mathrm{H}, \operatorname{ArH}), 8.20(\mathrm{~d}, J=7.2,1 \mathrm{H}$, $\mathrm{ArH}), 8.49$ (s, $1 \mathrm{H}, \mathrm{ArH})$. Anal. Calcd for $\mathrm{C}_{23} \mathrm{H}_{16} \mathrm{ClF}_{6} \mathrm{NO}_{4}$ : C: 53.14; H: 3.10; N: 2.69. Found: C: 53.29; H: 3.27; N: 2.83 .

4.4.5. Ethyl 4-[1-(3,5-dimethylbenzyl)-5-chloro-1H-indol-3-yl]2-hydroxy-4-oxobut-2-enoate (10e)

Mp 215-217 ${ }^{\circ} \mathrm{C}$, yield 89\%; ${ }^{1} \mathrm{H}$ NMR (DMSO- $\left.d_{6}\right): 1.25$ (t, $J=7.2$, $\left.3 \mathrm{H}, \mathrm{CH}_{3}\right), 2.20\left(\mathrm{~s}, 6 \mathrm{H}, \mathrm{CH}_{3}\right), 4.09\left(\mathrm{q}, J=7.2,2 \mathrm{H}, \mathrm{CH}_{2}\right), 5.37(\mathrm{~s}, 2 \mathrm{H}$, $\left.\mathrm{CH}_{2}\right), 6.17(\mathrm{~s}, 1 \mathrm{H}, \mathrm{ArH}), 6.86-6.89(\mathrm{~m}, 3 \mathrm{H}, 2 \mathrm{ArH}$ and $\mathrm{CH}), 7.13(\mathrm{~d}$
$J=8.8,1 \mathrm{H}, \operatorname{ArH}), 7.46(\mathrm{~d}, J=8.8,1 \mathrm{H}, \operatorname{ArH}), 8.13(\mathrm{~d}, J=6.1,1 \mathrm{H}$, ArH), $8.44(\mathrm{~s}, 1 \mathrm{H}, \mathrm{ArH})$. Anal. Calcd for $\mathrm{C}_{23} \mathrm{H}_{22} \mathrm{ClNO}_{4}$ : C: $67.07 ; \mathrm{H}$ : 5.38; N: 3.40. Found: C: 67.30; H: 5.41; N: 3.67.

4.4.6. Ethyl 4-[1-(2,4,6-trimethylbenzyl)-5-chloro-1H-indol-3yl]-2-hydroxy-4-oxobut-2-enoate (10f)

Mp 150-152 ${ }^{\circ} \mathrm{C}$, yield 97\%; ${ }^{1} \mathrm{H}$ NMR (DMSO- $\left.d_{6}\right): 1.27$ (t, $J=7.2$, $\left.3 \mathrm{H}, \mathrm{CH}_{3}\right), 2.16\left(\mathrm{~s}, 6 \mathrm{H}, \mathrm{CH}_{3}\right), 2.26\left(\mathrm{~s}, 3 \mathrm{H}, \mathrm{CH}_{3}\right), 4.26(\mathrm{q}, J=7.2,2 \mathrm{H}$, $\left.\mathrm{CH}_{2}\right), 5.44\left(\mathrm{~s}, 2 \mathrm{H}, \mathrm{CH}_{2}\right), 6.81(\mathrm{~s}, 1 \mathrm{H}, \mathrm{ArH}), 6.95(\mathrm{~s}, 2 \mathrm{H}, \operatorname{ArH}$ and $\mathrm{CH}), 7.35(\mathrm{~d}, J=8.5,1 \mathrm{H}, \mathrm{ArH}), 7.63(\mathrm{~d}, J=8.8,1 \mathrm{H}, \mathrm{ArH}), 8.17(\mathrm{~s}$, $1 \mathrm{H}, \operatorname{ArH}), 8.24(\mathrm{~s}, 1 \mathrm{H}, \mathrm{ArH})$. Anal. Calcd for $\mathrm{C}_{24} \mathrm{H}_{24} \mathrm{ClNO}_{4}$ : C: 67.68; H: 5.68; N: 3.29. Found: C: 67.85; H: 5.79; N: 3.16.

4.4.7. Ethyl 4-[1-(4-phenylbenzyl)-5-fluoro-1H-indol-3-yl]-2hydroxy-4-oxobut-2-enoate (11a)

Mp $168{ }^{\circ} \mathrm{C} \mathrm{dec}$, yield 92\%; ${ }^{1} \mathrm{H}$ NMR (DMSO-d $\left.d_{6}\right) 1.14(\mathrm{t}, J=7.3,3 \mathrm{H}$, $\left.\mathrm{CH}_{3}\right), 3.94\left(\mathrm{q}, \mathrm{J}=7.3,2 \mathrm{H}, \mathrm{CH}_{2}\right), 5.50\left(\mathrm{~s}, 2 \mathrm{H}, \mathrm{CH}_{2}\right), 6.25$ (br s, $\left.1 \mathrm{H}, \mathrm{OH}\right)$, 6.96-8.28 (m, $14 \mathrm{H}, \mathrm{ArH}$ and $\mathrm{CH})$. Anal. Calcd for $\mathrm{C}_{27} \mathrm{H}_{22} \mathrm{FNO}_{4}: \mathrm{C}$, 73.13; H, 5.00; N, 3.16. Found: C, 73.38; H, 4.16; N 3.01.

4.4.8. Ethyl 4-\{1-[4-(trifluoromethyl)benzyl]-5-fluoro- $1 H$-indol3-yl\}-2-hydroxy-4-oxobut-2-enoate (11b)

Mp $217^{\circ} \mathrm{C}$ dec, yield 60\%; ${ }^{1} \mathrm{H}$ NMR (DMSO- $\left.d_{6}\right): 1.23(\mathrm{t}, J=7.3$, $\left.3 \mathrm{H}, \mathrm{CH}_{3}\right), 4.09\left(\mathrm{q}, J=7.3,2 \mathrm{H}, \mathrm{CH}_{2}\right), 5.57\left(\mathrm{~s}, 2 \mathrm{H}, \mathrm{CH}_{2}\right), 6.17(\mathrm{~s}, 1 \mathrm{H}$, $\mathrm{OH}), 6.96(\mathrm{t}, J=9,1 \mathrm{H}, \operatorname{ArH}), 7.35-7.42(\mathrm{~m}, 4 \mathrm{H}, 3 \mathrm{ArH}$ and $\mathrm{CH})$, $7.68(\mathrm{~d}, J=8.1,2 \mathrm{H}, \mathrm{ArH}), 8.12(\mathrm{~s}, 1 \mathrm{H}, \mathrm{ArH}), 8.23(\mathrm{~s}, 1 \mathrm{H}, \mathrm{ArH})$. Anal. Calcd for $\mathrm{C}_{22} \mathrm{H}_{17} \mathrm{~F}_{4} \mathrm{NO}_{4}$ : C: 60.69; $\mathrm{H}$ : 3.94; N: 3.22. Found: $\mathrm{C}$ : 60.46; $\mathrm{H}: 4.11$; N: 3.37 .

\subsubsection{Ethyl 4-[1-(4-tert-butylbenzyl)-5-fluoro-1H-indol-3-yl]-2-} hydroxy-4-oxobut-2-enoate (11c)

Mp $227{ }^{\circ} \mathrm{C} \mathrm{dec}$, yield 88\%; ${ }^{1} \mathrm{H}$ NMR (DMSO- $\left.d_{6}\right): 1.20\left(\mathrm{~s}, 9 \mathrm{H}, \mathrm{CH}_{3}\right.$ ), $1.24\left(\mathrm{t}, J=6.9,3 \mathrm{H}, \mathrm{CH}_{3}\right), 4.07\left(\mathrm{~d}, J=6.9,2 \mathrm{H}, \mathrm{CH}_{2}\right), 5.38\left(\mathrm{~s}, 2 \mathrm{H}, \mathrm{CH}_{2}\right)$, $6.14(\mathrm{~s}, 1 \mathrm{H}, \mathrm{ArH}), 6.92-6.99(\mathrm{~m}, 1 \mathrm{H}, \mathrm{ArH}), 7.13-7.19(\mathrm{~m}, 2 \mathrm{H}, \mathrm{ArH}$ and $\mathrm{CH}$ ), 7.29-7.38 (m, 2H, ArH), 7.47 (d, J=9, 1H, ArH), 8.09 (d, $J=8.5,1 \mathrm{H}, \mathrm{ArH}), 8.51(\mathrm{~s}, 1 \mathrm{H}, \mathrm{ArH})$. Anal. Calcd for $\mathrm{C}_{25} \mathrm{H}_{26} \mathrm{FNO}_{4}$ : C: 70.91; H: 6.19; N: 3.31. Found: C: 71.04; H: 6.28; N: 3.51.

4.4.10. Ethyl 4-\{1-[2,4-bis(trifluoromethyl)benzyl]-5-fluoro-1Hindol-3-yl\}-2-hydroxy-4-oxobut-2-enoate (11d)

Mp 269-271 ${ }^{\circ} \mathrm{C}$, yield 99\%; ${ }^{1} \mathrm{H}$ NMR (DMSO- $\left.d_{6}\right) 1.23$ (t, $J=7.3$, $\left.3 \mathrm{H}, \mathrm{CH}_{3}\right), 4.10\left(\mathrm{q}, J=7.3,2 \mathrm{H}, \mathrm{CH}_{2}\right), 5.72\left(\mathrm{~s}, 2 \mathrm{H}, \mathrm{CH}_{2}\right), 6.21(\mathrm{~s}, 1 \mathrm{H}$, $\mathrm{OH}), 6.58-8.41(\mathrm{~m}, 8 \mathrm{H}, \mathrm{ArH}$ and $\mathrm{CH})$. Anal. Calcd for $\mathrm{C}_{23} \mathrm{H}_{16} \mathrm{~F} \mathrm{NO}_{4}$ : C, 54.88; H, 3.20; N, 2.78. Found: C, 54.96; H, 3.27; N, 3.35.

4.4.11. Ethyl 4-[1-(3,5-dimethylbenzyl)-5-fluoro-1H-indol-3-yl]2-hydroxy-4-oxobut-2-enoate (11e)

Mp 170-172 ${ }^{\circ} \mathrm{C}$, yield 93\%; ${ }^{1} \mathrm{H}$ NMR (DMSO- $\left.d_{6}\right): 1.23(\mathrm{t}, J=7.4$, $\left.3 \mathrm{H}, \mathrm{CH}_{3}\right), 2.19\left(\mathrm{~s}, 6 \mathrm{H}, \mathrm{CH}_{3}\right), 4.09\left(\mathrm{q}, J=7.4,2 \mathrm{H}, \mathrm{CH}_{2}\right), 5.34(\mathrm{~s}, 2 \mathrm{H}$, $\left.\mathrm{CH}_{2}\right), 6.16(\mathrm{~s}, 1 \mathrm{H}, \mathrm{ArH}), 6.86-6.98(\mathrm{~m}, 4 \mathrm{H}, 3 \mathrm{ArH}$ and $\mathrm{CH}), 7.41(\mathrm{~d}$, $J=8.5,1 \mathrm{H}, \mathrm{ArH}), 7.93(\mathrm{~s}, 1 \mathrm{H}, \mathrm{ArH}), 8.11$ (d, $J=6.4,1 \mathrm{H}, \mathrm{ArH}), 8.50$ (s, $1 \mathrm{H}, \mathrm{ArH}$ ). Anal. Calcd for $\mathrm{C}_{23} \mathrm{H}_{22} \mathrm{FNO}_{4}$ : C: 69.51; $\mathrm{H}: 6.09 ; \mathrm{N}$ : 3.52. Found: C: 69.76 ; $\mathrm{H}: 6.24 ; \mathrm{N}: 3.77$.

4.4.12. Ethyl 4-[1-(2,4,6-trimethylbenzyl)-5-fluoro-1H-indol-3yl]-2-hydroxy-4-oxobut-2-enoate (11f)

Mp 177-179 ${ }^{\circ} \mathrm{C}$, yield 94\%; ${ }^{1} \mathrm{H}$ NMR (DMSO- $\left.d_{6}\right): 1.20(\mathrm{t}, J=7.3$, $\left.3 \mathrm{H}, \mathrm{CH}_{3}\right), 2.16\left(\mathrm{~s}, 6 \mathrm{H}, \mathrm{CH}_{3}\right), 2.27\left(\mathrm{~s}, 3 \mathrm{H}, \mathrm{CH}_{3}\right), 4.05(\mathrm{q}, J=7.3,2 \mathrm{H}$, $\left.\mathrm{CH}_{2}\right), 5.28\left(\mathrm{~s}, 2 \mathrm{H}, \mathrm{CH}_{2}\right), 5.94(\mathrm{~d}, J=4.7,1 \mathrm{H}, \mathrm{ArH}), 6.19(\mathrm{~s}, 1 \mathrm{H}, \mathrm{ArH})$, 6.96-7.03 (m, $2 \mathrm{H}, \mathrm{ArH}$ and $\mathrm{CH}), 7.20(\mathrm{~s}, 1 \mathrm{H}, \operatorname{ArH}), 7.56(\mathrm{t}, J=8.5$, $1 \mathrm{H}, \mathrm{ArH}), 8.06(\mathrm{~m}, 1 \mathrm{H}, \mathrm{ArH})$. Anal. Calcd for $\mathrm{C}_{24} \mathrm{H}_{24} \mathrm{FNO}_{4}$ : C: 70.40; H: 5.91; N: 3.42. Found: C: 70.23; H: 6.07; N: 3.24

4.4.13. Ethyl 4-[1-(4-phenylbenzyl)-5-methoxy-1H-indol-3-yl]2-hydroxy-4-oxobut-2-enoate (12a)

Mp $164{ }^{\circ} \mathrm{C} \mathrm{dec}$, yield 95\%; ${ }^{1} \mathrm{H}$ NMR (DMSO- $\left.d_{6}\right) 1.24(\mathrm{t}, J=7.3,3 \mathrm{H}$, $\left.\mathrm{CH}_{3}\right), 3.75\left(\mathrm{~s}, 3 \mathrm{H}, \mathrm{OCH}_{3}\right) 3.93\left(\mathrm{q}, J=7.3,2 \mathrm{H}, \mathrm{CH}_{2}\right), 5.46\left(\mathrm{~s}, 2 \mathrm{H}, \mathrm{CH}_{2}\right)$, 
6.29 (br s, $1 \mathrm{H}, \mathrm{OH}), 6.68-8.18(\mathrm{~m}, 14 \mathrm{H}, \mathrm{ArH}$ and $\mathrm{CH}$ ). Anal. Calcd for $\mathrm{C}_{28} \mathrm{H}_{25} \mathrm{FNO}_{5}$ : C, 73.83; H, 5.53; N, 3.08. Found: C, 73.55; H, 5.27; N 3.01.

4.4.14. Ethyl 4-\{1-[4-(trifluoromethyl)benzyl]-5-methoxy-1Hindol-3-yl\}-2-hydroxy-4-oxobut-2-enoate (12b)

Mp $223{ }^{\circ} \mathrm{C}$ dec, yield 92\%; ${ }^{1} \mathrm{H}$ NMR (DMSO- $\left.d_{6}\right): 1.23(\mathrm{t}, J=7.3$, $\left.3 \mathrm{H}, \mathrm{CH}_{3}\right), 3.74\left(\mathrm{~s}, 3 \mathrm{H}, \mathrm{OCH}_{3}\right), 4.09\left(\mathrm{q}, \mathrm{J}=7.3,2 \mathrm{H}, \mathrm{CH}_{2}\right), 5.52(\mathrm{~s}, 2 \mathrm{H}$, $\left.\mathrm{CH}_{2}\right), 6.19(\mathrm{~s}, 1 \mathrm{H}, \mathrm{OH}), 6.74(\mathrm{~d}, J=8.8,1 \mathrm{H}, \mathrm{ArH}), 7.27(\mathrm{~d}, J=9.1$, 1H, ArH), 7.30-7.39 (m, 3H, 2ArH and $\mathrm{CH}), 7.68(\mathrm{~d}, J=7.9,2 \mathrm{H}$, ArH), $7.92(\mathrm{~s}, 1 \mathrm{H}, \mathrm{ArH}), 8.09$ (s, $1 \mathrm{H}, \mathrm{ArH})$. Anal. Calcd for $\mathrm{C}_{23} \mathrm{H}_{20} \mathrm{~F}_{3-}$ $\mathrm{NO}_{5}$ : C: 61.75; H: 4.51; N: 3.13. Found: C: 61.92; H: 4.38; N: 3.29.

4.4.15. Ethyl 4-[1-(4-tert-butylbenzyl)-5-methoxy-1H-indol-3yl]-2-hydroxy-4-oxobut-2-enoate (12c)

Mp 150-152 ${ }^{\circ} \mathrm{C}$, yield 91\%; ${ }^{1} \mathrm{H}$ NMR (DMSO- $d_{6}$ ): $1.16(\mathrm{~s}, 9 \mathrm{H}$, $\left.\mathrm{CH}_{3}\right), 1.20\left(\mathrm{t}, J=6.9,3 \mathrm{H}, \mathrm{CH}_{3}\right), 3.69\left(\mathrm{~s}, 3 \mathrm{H}, \mathrm{OCH}_{3}\right), 3.89(\mathrm{~d}, J=6.9$, $\left.2 \mathrm{H}, \mathrm{CH}_{2}\right), 5.30\left(\mathrm{~s}, 2 \mathrm{H}, \mathrm{CH}_{2}\right), 6.22(\mathrm{~s}, 1 \mathrm{H}, \mathrm{OH}), 6.65(\mathrm{~d}, J=8.5,1 \mathrm{H}$, $\operatorname{ArH}), 7.13(\mathrm{~d}, J=8.5,2 \mathrm{H}, \operatorname{ArH}), 7.28(\mathrm{~m}, 4 \mathrm{H}, 3 \mathrm{ArH}$ and $\mathrm{CH}), 7.82$ (s, $1 \mathrm{H}, \operatorname{ArH}), 8.42(\mathrm{~s}, 1 \mathrm{H}, \mathrm{ArH})$. Anal. Calcd for $\mathrm{C}_{25} \mathrm{H}_{27} \mathrm{NO}_{5}$ : C: 71.70; H: 6.71; N: 3.22. Found: C: 71.97; H: 6.91; N: 3.45 .

\subsubsection{Ethyl 4-\{1-[2,4-bis(trifluoromethyl)benzyl]-5-methoxy-} 1H-indol-3-yl\}-2-hydroxy-4-oxobut-2-enoate (12d)

Mp 166-168 ${ }^{\circ} \mathrm{C}$, yield 68\%; ${ }^{1} \mathrm{H}$ NMR (DMSO- $\left.d_{6}\right): 1.29(\mathrm{t}, J=7.3$, $\left.3 \mathrm{H}, \mathrm{CH}_{3}\right), 3.80\left(\mathrm{~s}, 3 \mathrm{H}, \mathrm{OCH}_{3}\right), 3.95\left(\mathrm{q}, J=7.3,2 \mathrm{H}, \mathrm{CH}_{2}\right), 5.81(\mathrm{~s}, 2 \mathrm{H}$, $\left.\mathrm{CH}_{2}\right), 6.76(\mathrm{~d}, J=8.1,1 \mathrm{H}, \mathrm{ArH}), 6.88-6.92(\mathrm{~m}, 2 \mathrm{H}, \mathrm{ArH}$ and $\mathrm{CH})$, $7.24(\mathrm{~d}, J=8.9,1 \mathrm{H}, \operatorname{ArH}), 7.80(\mathrm{~s}, 1 \mathrm{H}, \operatorname{ArH}), 7.95(\mathrm{~d}, J=8.1,1 \mathrm{H}$, $\mathrm{ArH}), 8.13(\mathrm{~s}, 1 \mathrm{H}, \mathrm{ArH}), 8.81(\mathrm{~s}, 1 \mathrm{H}, \mathrm{ArH})$. Anal. Calcd for $\mathrm{C}_{24} \mathrm{H}_{19} \mathrm{~F}_{6-}$ $\mathrm{NO}_{5}$ : C: 55.93; H: 3.72; N: 2.72. Found: C: 56.11; H: 3.98; N: 2.89.

4.4.17. Ethyl 4-[1-(3,5-dimethylbenzyl)-5-methoxy-1H-indol-3yl]-2-hydroxy-4-oxobut-2-enoate (12e)

Mp 240-242 ${ }^{\circ} \mathrm{C}$, yield 89\%; ${ }^{1} \mathrm{H}$ NMR (DMSO- $\left.d_{6}\right): 1.26(\mathrm{t}, J=7.2$, $\left.3 \mathrm{H}, \mathrm{CH}_{3}\right), 2.20\left(\mathrm{~s}, 6 \mathrm{H}, \mathrm{CH}_{3}\right), 3.76\left(\mathrm{~s}, 3 \mathrm{H}, \mathrm{OCH}_{3}\right), 3.95(\mathrm{q}, J=7.2,2 \mathrm{H}$, $\left.\mathrm{CH}_{2}\right), 5.33\left(\mathrm{~s}, 2 \mathrm{H}, \mathrm{CH}_{2}\right), 6.29(\mathrm{~s}, 1 \mathrm{H}, \mathrm{ArH}), 6.78(\mathrm{~d}, J=8.2,1 \mathrm{H}, \mathrm{ArH})$, 6.86-6.98 (m, 2H, ArH and CH), $7.32(\mathrm{~d}, J=8.8,1 \mathrm{H}, \mathrm{ArH}), 7.89(\mathrm{~s}$, $1 \mathrm{H}, \operatorname{ArH}), 8.10(\mathrm{~s}, 1 \mathrm{H}, \mathrm{ArH}), 8.48(\mathrm{~s}, 1 \mathrm{H}, \mathrm{ArH})$. Anal. Calcd for $\mathrm{C}_{24} \mathrm{H}_{25} \mathrm{NO}_{5}$ : C: 70.75; H: 6.18; N: 3.44. Found: C: 70.67; H: 6.40; $\mathrm{N}: 3.58$.

4.4.18. Ethyl 4-[1-(2,4,6-trimethylbenzyl)-5-methoxy-1H-indol3-yl]-2-hydroxy-4-oxobut-2-enoate (12f)

Mp 157-159 ${ }^{\circ} \mathrm{C}$, yield 98\%; ${ }^{1} \mathrm{H}$ NMR (DMSO- $\left.d_{6}\right): 1.27(\mathrm{t}, J=7.1$, $\left.3 \mathrm{H}, \mathrm{CH}_{3}\right), 2.17\left(\mathrm{~s}, 6 \mathrm{H}, \mathrm{CH}_{3}\right), 2.25\left(\mathrm{~s}, 3 \mathrm{H}, \mathrm{CH}_{3}\right), 3.79\left(\mathrm{~s}, 3 \mathrm{H}, \mathrm{OCH}_{3}\right)$, $4.26\left(\mathrm{q}, J=7.1,2 \mathrm{H}, \mathrm{CH}_{2}\right), 5.40\left(\mathrm{~s}, 2 \mathrm{H}, \mathrm{CH}_{2}\right), 6.79(\mathrm{~s}, 1 \mathrm{H}, \mathrm{ArH})$, 6.92-6.94 (m, 3H, 2ArH and $\mathrm{CH}), 7.48(\mathrm{~d}, J=8.8,1 \mathrm{H}, \mathrm{ArH}), 7.75$ (s, $1 \mathrm{H}, \operatorname{ArH}), 8.04(\mathrm{~s}, 1 \mathrm{H}, \mathrm{ArH})$. Anal. Calcd for $\mathrm{C}_{25} \mathrm{H}_{27} \mathrm{NO}_{5}$ : C: 71.24; H: 6.46; N: 3.32. Found: C: 71.51; H: 6.28; N: 3.46 .

4.5. General procedure for the synthesis of 4-[1-benzyl-1Hindol-3-yl]-2-hydroxy-4-oxobut-2-enoic acids (13-15 a-f)

Following the synthetic procedure previously reported by us, ${ }^{18,19,29,31}$ the appropriate 4-[1-benzyl-1H-indol-3-yl]-2-hydroxy-4-oxobut-2-enoate (10-12 a-f) $(1 \mathrm{mmol})$ was dissolved in methanol $(5 \mathrm{ml})$ and treated with $2 \mathrm{~N} \mathrm{NaOH}(5 \mathrm{ml}, 50 \mathrm{mmol})$. The reaction mixture was stirred at room temperature for $1.5 \mathrm{~h}$ and then acidified with conc. $\mathrm{HCl}$ to give the corresponding hydrolysed derivative. The desired products were crystallized from a mixture of ethanol and diethyl ether (1:4).

4.5.1. 4-[1-(4-Phenylbenzyl)-5-chloro-1H-indol-3-yl]-2hydroxy-4-oxobut-2-enoic acid (13a)

Mp $220{ }^{\circ} \mathrm{C} \mathrm{dec}$, yield 78\%; ${ }^{1} \mathrm{H}$ NMR (DMSO- $\left.d_{6}\right): 5.59\left(\mathrm{~s}, 2 \mathrm{H}, \mathrm{CH}_{2}\right)$, $7.03(\mathrm{~s}, 1 \mathrm{H}, \mathrm{ArH}), 7.33(\mathrm{t}, J=9,2 \mathrm{H}, \mathrm{ArH}), 7.39-7.45(\mathrm{~m}, 3 \mathrm{H}, 2 \mathrm{ArH}$ and $\mathrm{CH}$ ), 7.59-7.63 (m, 4H, ArH), 7.73 (d, $J=9,2 \mathrm{H}, \mathrm{ArH}), 8.21$ (s, $1 \mathrm{H}, \mathrm{ArH}), 9.18(\mathrm{~s}, 1 \mathrm{H}, \mathrm{ArH})$. Anal. Calcd for $\mathrm{C}_{25} \mathrm{H}_{18} \mathrm{ClNO}_{4}$ : C: 69.53; H: 4.20; N: 3.24. Found: C: 69.64; H: 4.42; N: 3.38.

\subsubsection{4-\{1-[4-(Trifluoromethyl)benzyl]-5-chloro-1H-indol-3-} yl\}-2-hydroxy-4-oxobut-2-enoic acid (13b)

Mp $176-178{ }^{\circ} \mathrm{C}$, yield $30 \%$; ${ }^{1} \mathrm{H}$ NMR (DMSO- $d_{6}$ ): $5.63(\mathrm{~s}, 2 \mathrm{H}$, $\left.\mathrm{CH}_{2}\right), 6.98(\mathrm{~s}, 1 \mathrm{H}, \mathrm{CH}), 7.30(\mathrm{~d}, J=9,1 \mathrm{H}, \mathrm{ArH}), 7.49(\mathrm{~d}, J=8,2 \mathrm{H}$, ArH), 7.62-7.72 (m, 3H, ArH), 8.21 (s, 1H, ArH), 9.07 (s, 1H, ArH). Anal. Calcd for $\mathrm{C}_{20} \mathrm{H}_{13} \mathrm{ClF}_{3} \mathrm{NO}_{4}$ : C: $56.69 ; \mathrm{H}: 3.09$; N: 3.31. Found: C: 56.87 ; $: 3.32 ; \mathrm{N}: 3.49$.

\subsubsection{4-[1-(4-tert-Butylbenzyl)-5-chloro-1H-indol-3-yl]-2-} hydroxy-4-oxobut-2-enoic acid (13c)

Mp $109-111^{\circ} \mathrm{C}$, yield $51 \%$; ${ }^{1} \mathrm{H}$ NMR (DMSO- $\left.d_{6}\right): 1.20(\mathrm{~s}, 9 \mathrm{H}$, $\left.\mathrm{CH}_{3}\right), 5.46\left(\mathrm{~s}, 2 \mathrm{H}, \mathrm{CH}_{2}\right), 6.98(\mathrm{~s}, 1 \mathrm{H}, \mathrm{CH}), 7.25-7.35(\mathrm{~m}, 5 \mathrm{H}, \mathrm{ArH})$, $7.69(\mathrm{~d}, J=9.1,1 \mathrm{H}, \mathrm{ArH}), 8.20(\mathrm{~s}, 1 \mathrm{H}, \mathrm{ArH}), 9.06(\mathrm{~s}, 1 \mathrm{H}, \mathrm{ArH})$. Anal. Calcd for $\mathrm{C}_{23} \mathrm{H}_{22} \mathrm{ClNO}_{4}$ : C: 67.07; $\mathrm{H}$ : 5.38, N: 3.40. Found: C: 67.24; H: 5.21, N: 3.29.

\subsubsection{4-\{1-[2,4-Bis(trifluoromethyl)benzyl]-5-chloro-1H-indol-} 3-yl\}-2-hydroxy-4-oxobut-2-enoic acid (13d)

Mp 365-367 ${ }^{\circ} \mathrm{C}$, yield 38\%; ${ }^{1} \mathrm{H}$ NMR (DMSO-d ${ }_{6}$ ): 5.85 (s, $2 \mathrm{H}$, $\left.\mathrm{CH}_{2}\right), 6.79(\mathrm{t}, J=8.5,1 \mathrm{H}, \mathrm{ArH}), 6.94(\mathrm{~s}, 1 \mathrm{H}, \mathrm{CH}), 7.32(\mathrm{~d}, J=9.6$, $1 \mathrm{H}, \mathrm{ArH}), 7.45(\mathrm{~d}, J=8.5,1 \mathrm{H}, \operatorname{ArH}), 7.95(\mathrm{~d}, J=7.5,1 \mathrm{H}, \mathrm{ArH}), 8.14$ (s, $1 \mathrm{H}, \mathrm{ArH}), 8.28(\mathrm{~s}, 1 \mathrm{H}, \mathrm{ArH}), 8.97(\mathrm{~s}, 1 \mathrm{H}, \mathrm{ArH})$. Anal. Calcd for $\mathrm{C}_{21}$ $\mathrm{H}_{12} \mathrm{ClF}_{6} \mathrm{NO}_{4}$ : C: $51.29 ; \mathrm{H}: 2.46 ; \mathrm{N}: 2.85$. Found: $\mathrm{C}: 51.42 ; \mathrm{H}: 2.77 ; \mathrm{N}$, 3.03 .

\subsubsection{4-[1-(3,5-Dimethylbenzyl)-5-chloro-1H-indol-3-yl]-2- hydroxy-4-oxobut-2-enoic acid (13e)}

Mp 157-159 ${ }^{\circ} \mathrm{C}$, yield 71\%; ${ }^{1} \mathrm{H}$ NMR (DMSO- $d_{6}$ ): $2.21(\mathrm{~s}, 6 \mathrm{H}$, $\left.\mathrm{CH}_{3}\right), 5.44\left(\mathrm{~s}, 2 \mathrm{H}, \mathrm{CH}_{2}\right), 6.94(\mathrm{~d}, J=7.5,3 \mathrm{H}, \mathrm{ArH}), 6.98(\mathrm{~s}, 1 \mathrm{H}, \mathrm{CH})$, $7.31(\mathrm{~d}, J=8.9,1 \mathrm{H}, \operatorname{ArH}), 7.65(\mathrm{~d}, J=8.9,1 \mathrm{H}, \operatorname{ArH}), 8.21(\mathrm{~s}, 1 \mathrm{H}$, ArH), 9.05 (s, $1 \mathrm{H}, \mathrm{ArH})$. Anal. Calcd for $\mathrm{C}_{21} \mathrm{H}_{18} \mathrm{ClNO}_{4}$ : C: $65.71 ; \mathrm{H}$ : 4.73; N: 3.65. Found: C: $65.85 ; \mathrm{H}: 4.68 ; \mathrm{N}: 3.94$.

4.5.6. 4-[1-(2,4,6-Trimethylbenzyl)-5-chloro-1H-indol-3-yl]-2hydroxy-4-oxobut-2-enoic acid (13f)

Mp 238-240 ${ }^{\circ} \mathrm{C}$, yield 59\%; ${ }^{1} \mathrm{H}$ NMR (DMSO- $\left.d_{6}\right): 2.18(\mathrm{~s}, 6 \mathrm{H}$, $\left.\mathrm{CH}_{3}\right), 2.24\left(\mathrm{~s}, 3 \mathrm{H}, \mathrm{CH}_{3}\right), 5.42\left(\mathrm{~s}, 2 \mathrm{H}, \mathrm{CH}_{2}\right), 6.82(\mathrm{~s}, 1 \mathrm{H}, \mathrm{CH}), 6.97(\mathrm{~s}$, $2 \mathrm{H}, \mathrm{ArH}), 7.20-7.23$ (m, 1H, ArH), 7.61-7.64 (m, 1H, ArH), 7.92$7.95(\mathrm{~m}, 1 \mathrm{H}, \mathrm{ArH}), 8.15(\mathrm{~s}, 1 \mathrm{H}, \mathrm{ArH})$. Anal. Calcd for $\mathrm{C}_{22} \mathrm{H}_{20} \mathrm{ClNO}_{4}$ : C: 66.42; H: 5.07; N: 3.52. Found: C: 66.55; H: 5.19; N: 3.41 .

\subsubsection{4-[1-(4-Phenylbenzyl)-5-fluoro-1H-indol-3-yl]-2-} hydroxy-4-oxobut-2-enoic acid (14a)

Mp $173-175{ }^{\circ} \mathrm{C}$, yield $42 \%$; ${ }^{1} \mathrm{H}$ NMR (DMSO- $d_{6}$ ): $5.56(\mathrm{~s}, 2 \mathrm{H}$, $\left.\mathrm{CH}_{2}\right), 6.98(\mathrm{~s}, 1 \mathrm{H}, \mathrm{ArH}), 7.15(\mathrm{t}, J=8.1,1 \mathrm{H}, \operatorname{ArH}), 7.32(\mathrm{~d}, J=6.8$, $1 \mathrm{H}, \mathrm{ArH}), 7.35-7.45(\mathrm{~m}, 4 \mathrm{H}, 3 \mathrm{ArH}$ and $\mathrm{CH}), 7.59-7.70(\mathrm{~m}, 5 \mathrm{H}$, ArH), 9.08 (s, $1 \mathrm{H}, \mathrm{ArH})$. Anal. Calcd for $\mathrm{C}_{25} \mathrm{H}_{18} \mathrm{FNO}_{4}$ : C: $72.28 ; \mathrm{H}$ : 4.37; N: 3.37. Found: C: 72.44; H: 4.15; N: 3.21.

4.5.8. 4-\{1-[4-(Trifluoromethyl)benzyl]-5-fluoro-1H-indol-3yl\}-2-hydroxy-4-oxobut-2-enoic acid (14b)

Mp $174{ }^{\circ} \mathrm{C} \mathrm{dec}$, yield $48 \%$; ${ }^{1} \mathrm{H}$ NMR (DMSO- $\left.d_{6}\right): 5.64\left(\mathrm{~s}, 2 \mathrm{H}, \mathrm{CH}_{2}\right)$, $6.98(\mathrm{~s}, 1 \mathrm{H}, \mathrm{CH}), 7.16(\mathrm{t}, J=9.4,1 \mathrm{H}, \mathrm{ArH}), 7.52(\mathrm{~d}, J=8.2,2 \mathrm{H}, \mathrm{ArH})$, $7.63(\mathrm{~d}, J=8.9,1 \mathrm{H}, \operatorname{ArH}), 7.71(\mathrm{~d}, J=8.2,1 \mathrm{H}, \operatorname{ArH}), 7.91$ (d, $J=9.4$, $1 \mathrm{H}, \mathrm{ArH}), 9.08(\mathrm{~s}, 1 \mathrm{H}, \mathrm{ArH})$. Anal. Calcd for $\mathrm{C}_{20} \mathrm{H}_{13} \mathrm{~F}_{4} \mathrm{NO}_{4}$ : C: 58.98; H: 3.22; N: 3.44. Found: C: 59.14; H: 3.47; N: 3.24.

\subsubsection{4-[1-(4-tert-Butylbenzyl)-5-fluoro-1H-indol-3-yl]-2-} hydroxy-4-oxobut-2-enoic acid (14c)

Mp 186-188 ${ }^{\circ} \mathrm{C}$, yield 55\%; ${ }^{1} \mathrm{H}$ NMR (DMSO- $d_{6}$ ): $1.22(\mathrm{~s}, 9 \mathrm{H}$, $\left.\mathrm{CH}_{3}\right), 5.49\left(\mathrm{~s}, 2 \mathrm{H}, \mathrm{CH}_{2}\right), 6.98(\mathrm{~s}, 1 \mathrm{H}, \mathrm{CH}), 7.11-7.20(\mathrm{~m}, 1 \mathrm{H}, \mathrm{ArH})$, 7.29-7.37 (m, 4H, ArH), 7.68-7.72 (m, 1H, ArH), 7.99 (d, J=9.4, 
$1 \mathrm{H}, \mathrm{ArH}), 9.08(\mathrm{~s}, 1 \mathrm{H}, \mathrm{ArH})$. Anal. Calcd for $\mathrm{C}_{23} \mathrm{H}_{22} \mathrm{FNO}_{4}$ : C: 69.86; $\mathrm{H}$ : 5.61; N: 3.54. Found: C: 69.99; H: 5.52; N: 3.59.

4.5.10. 4-\{1-[2,4-Bis(trifluoromethyl)benzyl]-5-fluoro- $1 H$-indol3-yl\}-2-hydroxy-4-oxobut-2-enoic acid (14d)

Mp 237-239 ${ }^{\circ} \mathrm{C}$, yield 61\%; ${ }^{1} \mathrm{H}$ NMR (DMSO- $d_{6}$ ): $5.82(\mathrm{~s}, 2 \mathrm{H}$, $\left.\mathrm{CH}_{2}\right), 6.79(\mathrm{~d}, J=8.1,1 \mathrm{H}, \mathrm{ArH}), 6.95(\mathrm{~s}, 1 \mathrm{H}, \mathrm{CH}), 7.16(\mathrm{t}, J=9.4$, $1 \mathrm{H}, \operatorname{ArH}), 7.39$ (d, $J=8.9,1 \mathrm{H}, \mathrm{ArH}), 7.97(\mathrm{~d}, J=9.4,1 \mathrm{H}, \mathrm{ArH}), 8.25$ $(\mathrm{s}, 1 \mathrm{H}, \operatorname{ArH}), 8.97(\mathrm{~s}, 1 \mathrm{H}, \operatorname{ArH})$. Anal. Calcd for $\mathrm{C}_{21} \mathrm{H}_{12} \mathrm{~F}_{7} \mathrm{NO}_{4}$ : C: 53.07; H: 2.54; N: 2.95. Found: C: 53.25; H: 2.32; N: 3.09 .

\subsubsection{4-[1-(3,5-Dimethylbenzyl)-5-fluoro-1H-indol-3-yl]-2-} hydroxy-4-oxobut-2-enoic acid (14e)

Mp 231-233 ${ }^{\circ} \mathrm{C}$, yield 98\%; ${ }^{1} \mathrm{H}$ NMR (DMSO- $\left.d_{6}\right): 2.21(\mathrm{~s}, 6 \mathrm{H}$, $\left.\mathrm{CH}_{3}\right), 5.43\left(\mathrm{~s}, 2 \mathrm{H}, \mathrm{CH}_{2}\right), 6.92-6.99(\mathrm{~m}, 4 \mathrm{H}, 3 \mathrm{ArH}$ and $\mathrm{CH}), 7.13-$ $7.20(\mathrm{~m}, 1 \mathrm{H}, \mathrm{ArH}), 7.61-7.65(\mathrm{~m}, 1 \mathrm{H}, \mathrm{ArH}), 7.88-7.92(\mathrm{~m}, 1 \mathrm{H}$, $\mathrm{ArH}), 9.05$ (s, $1 \mathrm{H}, \mathrm{ArH})$. Anal. Calcd for $\mathrm{C}_{21} \mathrm{H}_{18} \mathrm{FNO}_{4}$ : C: 68.66; $\mathrm{H}$ : 4.94; N: 3.81. Found: C: $68.50 ; \mathrm{H}: 5.18 ; \mathrm{N}: 3.94$.

4.5.12. 4-[1-(2,4,6-Trimethylbenzyl)-5-fluoro-1H-indol-3-yl]-2hydroxy-4-oxobut-2-enoic acid (14f)

Mp $110-112{ }^{\circ} \mathrm{C}$, yield $14 \% ;{ }^{1} \mathrm{H}$ NMR (DMSO- $\left.d_{6}\right): 2.17(\mathrm{~s}, 6 \mathrm{H}$, $\left.\mathrm{CH}_{3}\right), 2.26\left(\mathrm{~s}, 3 \mathrm{H}, \mathrm{CH}_{3}\right), 5.44\left(\mathrm{~s}, 2 \mathrm{H}, \mathrm{CH}_{2}\right), 6.80(\mathrm{~s}, 1 \mathrm{H}, \mathrm{CH}), 6.95(\mathrm{~s}$, $2 \mathrm{H}, \operatorname{ArH}), 7.19-7.23(\mathrm{~m}, 1 \mathrm{H}, \mathrm{ArH}), 7.62-7.66(\mathrm{~m}, 1 \mathrm{H}, \mathrm{ArH}), 7.91-$ $7.95(\mathrm{~m}, 1 \mathrm{H}, \mathrm{ArH}), 8.13(\mathrm{~s}, 1 \mathrm{H}, \mathrm{ArH})$. Anal. Calcd for $\mathrm{C}_{22} \mathrm{H}_{20} \mathrm{FNO}_{4}$ : C: $69.28 ; \mathrm{H}: 5.29$; N: 3.67. Found: C: 69.46; H: 5.15; N: 3.48 .

\subsubsection{4-[1-(4-Phenylbenzyl)-5-methoxy-1H-indol-3-yl]-2-} hydroxy-4-oxobut-2-enoic acid (15a)

Mp 170-172 ${ }^{\circ} \mathrm{C}$, yield 64\%; ${ }^{1} \mathrm{H}$ NMR (DMSO- $\left.d_{6}\right): 3.78(\mathrm{~s}, 3 \mathrm{H}$, $\left.\mathrm{OCH}_{3}\right), 5.52\left(\mathrm{~s}, 2 \mathrm{H}, \mathrm{CH}_{2}\right), 6.90(\mathrm{~d}, J=8.5,1 \mathrm{H}, \operatorname{ArH}), 6.97(\mathrm{~s}, 1 \mathrm{H}$, ArH), $7.34(\mathrm{~d}, J=7.3,1 \mathrm{H}, \mathrm{ArH}), 7.40-7.45(\mathrm{~m}, 4 \mathrm{H}, 3 \mathrm{ArH}$ and $\mathrm{CH})$, $7.55(\mathrm{~d}, J=8.9,1 \mathrm{H}, \mathrm{ArH}), 7.59-7.63(\mathrm{~m}, 4 \mathrm{H}, \mathrm{ArH}), 7.74(\mathrm{~s}, 1 \mathrm{H}$, ArH), 8.97 (s, $1 \mathrm{H}, \mathrm{ArH})$. Anal. Calcd for $\mathrm{C}_{26} \mathrm{H}_{21} \mathrm{NO}_{5}$ : C: $73.06 ; \mathrm{H}$ : 4.95; N: 3.28. Found: C: 73.26; $\mathrm{H}: 4.81 ; \mathrm{N}: 3.08$.

\subsubsection{4-\{1-[4-(Trifluoromethyl)benzyl]-5-methoxy-1H-indol-} 3-yl\}-2-hydroxy-4-oxobut-2-enoic acid (15b)

Mp 178-180 ${ }^{\circ} \mathrm{C}$, yield $72 \% ;{ }^{1} \mathrm{H}$ NMR (DMSO-d $\left.{ }_{6}\right) 3.80(\mathrm{~s}, 3 \mathrm{H}$, $\left.\mathrm{OCH}_{3}\right), 5.61\left(\mathrm{~s}, 2 \mathrm{H}, \mathrm{CH}_{2}\right), 6.97-7.78(\mathrm{~m}, 8 \mathrm{H}, \mathrm{ArH}$ and $\mathrm{CH}), 8.98(\mathrm{~s}$, $1 \mathrm{H}, \mathrm{ArH}$ ). Anal. Calcd for $\mathrm{C}_{21} \mathrm{H}_{16} \mathrm{~F}_{3} \mathrm{NO}_{5}$ : $\mathrm{C}, 60.15 ; \mathrm{H}, 3.38 ; \mathrm{N}, 3.34$. Found: C, 60.23; H, 3.57; N, 3.56.

\subsubsection{4-[1-(4-tert-Butylbenzyl)-5-methoxy-1H-indol-3-yl]-2-} hydroxy-4-oxobut-2-enoic acid (15c)

Mp 177-179 ${ }^{\circ} \mathrm{C}$, yield 26\%; ${ }^{1} \mathrm{H}$ NMR (DMSO- $d_{6}$ ): $1.19(\mathrm{~s}, 9 \mathrm{H}$, $\left.\mathrm{CH}_{3}\right), 3.74\left(\mathrm{~s}, 3 \mathrm{H}, \mathrm{OCH}_{3}\right), 5.42\left(\mathrm{~s}, 2 \mathrm{H}, \mathrm{CH}_{2}\right), 6.88(\mathrm{~d}, J=9,1 \mathrm{H}, \mathrm{ArH})$, $6.95(\mathrm{~s}, 1 \mathrm{H}, \mathrm{CH}), 7.29$ (d, J = 8.5, 4H, ArH), $7.52(\mathrm{~d}, J=9,1 \mathrm{H}, \operatorname{ArH})$, $7.70(\mathrm{~s}, 1 \mathrm{H}, \mathrm{ArH}), 8.94(\mathrm{~s}, 1 \mathrm{H}, \mathrm{ArH})$. Anal. Calcd for $\mathrm{C}_{24} \mathrm{H}_{25} \mathrm{NO}_{5}$ : C: 70.74; H: 6.18; N: 3.44. Found: C: 70.92; H: 6.34; N: 3.70.

\subsubsection{4-\{1-[2,4-Bis(trifluoromethyl)benzyl]-5-methoxy-1H- indol-3-yl\}-2-hydroxy-4-oxobut-2-enoic acid (15d)}

Mp 198-200 ${ }^{\circ} \mathrm{C}$, yield $72 \% ;{ }^{1} \mathrm{H}$ NMR (DMSO- $\left.d_{6}\right): 3.80(\mathrm{~s}, 3 \mathrm{H}$, $\left.\mathrm{OCH}_{3}\right), 5.80\left(\mathrm{~s}, 2 \mathrm{H}, \mathrm{CH}_{2}\right), 6.79(\mathrm{~d}, J=8.1,1 \mathrm{H}, \mathrm{ArH}), 6.89(\mathrm{~s}, 1 \mathrm{H}$, $\operatorname{ArH}), 6.92(\mathrm{~s}, 1 \mathrm{H}, \mathrm{CH}), 7.26(\mathrm{~d}, J=8.9,1 \mathrm{H}, \operatorname{ArH}), 7.80(\mathrm{~s}, 1 \mathrm{H}, \operatorname{ArH})$, $7.96(\mathrm{~d}, J=8.1,1 \mathrm{H}, \operatorname{ArH}), 8.13(\mathrm{~s}, 1 \mathrm{H}, \operatorname{ArH}), 8.86$ (s, 1H, ArH). Anal. Calcd for $\mathrm{C}_{22} \mathrm{H}_{15} \mathrm{~F}_{6} \mathrm{NO}_{5}$ : C: $54.22 ; \mathrm{H}: 3.10 ; \mathrm{N}: 2.87$. Found: C: 54.35; H: 3.32; N: 3.04 .

4.5.17. 4-[1-(3,5-Dimethylbenzyl)-5-methoxy-1H-indol-3-yl]-2hydroxy-4-oxobut-2-enoic acid (15e)

Mp $180-182{ }^{\circ} \mathrm{C}$, yield $45 \% ;{ }^{1} \mathrm{H}$ NMR (DMSO- $\left.d_{6}\right): 2.20(\mathrm{~s}, 6 \mathrm{H}$, $\left.\mathrm{CH}_{3}\right), 3.78\left(\mathrm{~s}, 3 \mathrm{H}, \mathrm{OCH}_{3}\right), 5.38\left(\mathrm{~s}, 2 \mathrm{H}, \mathrm{CH}_{2}\right), 6.87-6.96(\mathrm{~m}, 5 \mathrm{H}$, $4 \operatorname{ArH}$ and $\mathrm{CH}$ ), 7.47 (d, J=9.1, $1 \mathrm{H} \mathrm{ArH}), 7.74(\mathrm{~s}, 1 \mathrm{H}, \mathrm{ArH}), 8.87$ (s,
$1 \mathrm{H}, \mathrm{ArH})$. Anal. Calcd for $\mathrm{C}_{22} \mathrm{H}_{21} \mathrm{NO}_{5}$ : C: $69.65 ; \mathrm{H}: 5.58$; N: 3.69 . Found: C: 69.46 ; $\mathrm{H}: 5.81 ; \mathrm{N}: 3.77$.

4.5.18. 4-[1-(2,4,6-Trimethylbenzyl)-5-methoxy-1H-indol-3-yl]2-hydroxy-4-oxobut-2-enoic acid (15f)

Mp 204-206 ${ }^{\circ} \mathrm{C}$, yield 49\%; ${ }^{1} \mathrm{H}$ NMR (DMSO- $d_{6}$ ): $2.18(\mathrm{~s}, 6 \mathrm{H}$, $\left.\mathrm{CH}_{3}\right), 2.27\left(\mathrm{~s}, 3 \mathrm{H}, \mathrm{CH}_{3}\right), 3.80\left(\mathrm{~s}, 3 \mathrm{H}, \mathrm{OCH}_{3}\right), 5.40\left(\mathrm{~s}, 2 \mathrm{H}, \mathrm{CH}_{2}\right), 6.76$ (s, 1H, CH), 6.92-6.95 (m, 3H, ArH), $7.51(\mathrm{~d}, J=9,1 \mathrm{H}, \mathrm{ArH}), 7.76$ $(\mathrm{s}, 1 \mathrm{H}, \mathrm{ArH}), 8.00(\mathrm{~s}, 1 \mathrm{H}, \mathrm{ArH})$. Anal. Calcd for $\mathrm{C}_{23} \mathrm{H}_{23} \mathrm{NO}_{5}$ : C: 70.22; H: 5.89; N: 3.56. Found: C: 69.98; H: 5.97; N: 3.85.

4.6. General procedure for the synthesis of 4-[1-benzyl-1Hindol-3-oyl)]-3-hydroxyfuran-2(5H)-ones (16-18 a-f)

Adopting the synthetic procedure previously reported by $\mathrm{us}^{32}$, a solution of $40 \%$ aqueous formaldehyde in water $(4 \mathrm{ml})$ was added to a mixture of 13-15 a-f $(1 \mathrm{mmol})$ in diethyl ether $(5 \mathrm{ml})$. The stirring was then continued until clear layers were formed (usually within 1-2 h). The clear, aqueous bottom layer was removed and the organic layer extracted twice with $5 \mathrm{ml}$ of water. The combined aqueous extracts were cooled followed by acidification with $3 \mathrm{ml}$ of concentrated hydrochloric acid. The corresponding furanone precipitate was collected, dried and recrystallized from ethanol.

\subsubsection{4-[1-(4-Phenylbenzyl)-5-chloro-1H-indol-3-yl)-3-} hydroxyfuran-2(5H)-one (16a)

Mp 199-201 ${ }^{\circ} \mathrm{C}$, yield 69\%; ${ }^{1} \mathrm{H}$ NMR (DMSO- $d_{6}$ ): $5.12(\mathrm{~s}, 2 \mathrm{H}$, $\left.\mathrm{CH}_{2}\right), 5.60\left(\mathrm{~s}, 2 \mathrm{H}, \mathrm{CH}_{2}\right), 7.29-8.81(\mathrm{~m}, 13 \mathrm{H}, \mathrm{ArH})$. Anal. Calcd for $\mathrm{C}_{26-}$ $\mathrm{H}_{18} \mathrm{ClNO}_{4}$ : C: 70.35; H: 4.09; N: 3.16. Found: C: 70.54; H: 4.29; N: 3.42 .

\subsubsection{4-[1-(4-Trifluoromethylbenzyl)-5-chloro-1H-indol-3-yl)-} 3-hydroxyfuran-2(5H)-one (16b)

Mp 212-214 ${ }^{\circ} \mathrm{C}$, yield $32 \% ;{ }^{1} \mathrm{H}$ NMR (DMSO- $d_{6}$ ): 5.12 (s, $2 \mathrm{H}$, $\left.\mathrm{CH}_{2}\right), 5.59\left(\mathrm{~s}, 2 \mathrm{H}, \mathrm{CH}_{2}\right), 7.10-7.85(\mathrm{~m}, 7 \mathrm{H}, \mathrm{ArH}), 8.79$ (s, 1H, ArH). Anal. Calcd for $\mathrm{C}_{21} \mathrm{H}_{13} \mathrm{ClF}_{3} \mathrm{NO}_{4}$ : C: $57.88 ; \mathrm{H}: 3.01$; $\mathrm{N}$ : 3.21. Found: C: $57.63 ; \mathrm{H}: 3.22 ; \mathrm{N}: 3.41$.

\subsubsection{4-[1-(4-tert-Butylbenzyl)-5-chloro-1H-indol-3-yl]-3-} hydroxyfuran-2(5H)-one (16c)

Mp $179-181{ }^{\circ} \mathrm{C}$, yield $26 \% ;{ }^{1} \mathrm{H}$ NMR (DMSO- $\left.d_{6}\right): 1.23(\mathrm{~s}, 9 \mathrm{H}$, $\left.\mathrm{CH}_{3}\right), 5.13\left(\mathrm{~s}, 2 \mathrm{H}, \mathrm{CH}_{2}\right), 5.51\left(\mathrm{~s}, 2 \mathrm{H}, \mathrm{CH}_{2}\right), 7.26(\mathrm{t}, J=8.3,3 \mathrm{H}, \mathrm{ArH})$, $7.33(\mathrm{t}, J=8.3,3 \mathrm{H}, \operatorname{ArH}), 7.65(\mathrm{~d}, J=8.8,1 \mathrm{H}, \operatorname{ArH}), 8.22(\mathrm{~s}, 1 \mathrm{H}$, ArH), 8.77 (s, $1 \mathrm{H}, \mathrm{OH}$ ). Anal. Calcd for $\mathrm{C}_{24} \mathrm{H}_{22} \mathrm{ClNO}_{4}: \mathrm{C}: 68.00 ; \mathrm{H}$ : 5.23; N: 3.30. Found: C: 68.11; H: 5.34; N: 3.21 .

4.6.4. 4-\{1-[2,4-Bis(trifluoromethyl)benzyl]-5-chloro-1H-indol3-yl\}-3-hydroxyfuran-2(5H)-one (16d)

Mp 231-233 ${ }^{\circ} \mathrm{C}$, yield $44 \%$; ${ }^{1} \mathrm{H}$ NMR (DMSO-d $)_{6}$ ): $5.10(\mathrm{~s}, 2 \mathrm{H}$, $\left.\mathrm{CH}_{2}\right), 5.87\left(\mathrm{~s}, 2 \mathrm{H}, \mathrm{CH}_{2}\right), 6.88-8.69(\mathrm{~m}, 7 \mathrm{H}, \mathrm{ArH})$. Anal. Calcd for $\mathrm{C}_{22}$ $\mathrm{H}_{12} \mathrm{ClF}_{6} \mathrm{NO}_{4}$ : C, 52.45; H, 2.40; N, 2.78. Found: C, 52.39; H, 2.52; N, 2.89 .

4.6.5. 4-[1-(3,5-Dimethylbenzyl)-5-chloro-1H-indol-3-yl]-3hydroxyfuran-2(5H)-one (16e)

Mp 215-217 ${ }^{\circ} \mathrm{C}$, yield 63\%; ${ }^{1} \mathrm{H}$ NMR (DMSO- $d_{6}$ ): 2.19 (s, $6 \mathrm{H}$, $\left.\mathrm{CH}_{3}\right), 5.10$ (s, $\left.2 \mathrm{H}, \mathrm{CH}_{2}\right), 5.44\left(\mathrm{~s}, 2 \mathrm{H}, \mathrm{CH}_{2}\right), 6.91$ (s, 3H, ArH), 7.28 $(\mathrm{d}, J=8.5,1 \mathrm{H}, \mathrm{ArH}), 7.58(\mathrm{~d}, J=8.5,1 \mathrm{H}, \mathrm{ArH}), 8.20(\mathrm{~s}, 1 \mathrm{H}, \mathrm{ArH})$, $8.70(\mathrm{~s}, 1 \mathrm{H}, \mathrm{ArH})$. Anal. Calcd for $\mathrm{C}_{22} \mathrm{H}_{18} \mathrm{ClNO}_{4}$ : C: 66.75; $\mathrm{H}: 4.58$; $\mathrm{N}: 3.54$. Found: C: $66.63 ; \mathrm{H}: 4.75 ; \mathrm{N}: 3.70$.

\subsubsection{4-[1-(2,4,6-Trimethylbenzyl)-5-chloro-1H-indol-3-yl]-3- hydroxyfuran-2(5H)-one (16f)}

Mp 228-230 ${ }^{\circ} \mathrm{C}$, yield 48\%; ${ }^{1} \mathrm{H}$ NMR (DMSO- $d_{6}$ ): 2.19 (s, 6H, $\left.\mathrm{CH}_{3}\right), 2.25\left(\mathrm{~s}, 3 \mathrm{H}, \mathrm{CH}_{3}\right), 4.94\left(\mathrm{~s}, 2 \mathrm{H}, \mathrm{CH}_{2}\right), 5.38\left(\mathrm{~s}, 2 \mathrm{H}, \mathrm{CH}_{2}\right), 6.94$ (s, $2 \mathrm{H}, \operatorname{ArH}), 7.37(\mathrm{~d}, J=8.5,1 \mathrm{H}, \mathrm{ArH}), 7.79(\mathrm{~d}, J=8.5,1 \mathrm{H}, \mathrm{ArH})$, 
8.24 (s, 2H, ArH). Anal. Calcd for $\mathrm{C}_{23} \mathrm{H}_{20} \mathrm{ClNO}_{4}$ : C: $67.40 ; \mathrm{H}: 4.92 ; \mathrm{N}$ : 3.42. Found: C: 67.55 ; $\mathrm{H}: 5.02$; N: 3.67 .

\subsubsection{4-[1-(4-Phenylbenzyl)-5-fluoro-1H-indol-3-yl)-3-} hydroxyfuran-2(5H)-one (17a)

Mp 165-167 ${ }^{\circ} \mathrm{C}$, yield 41\%; ${ }^{1} \mathrm{H}$ NMR $\left(\mathrm{CDCl}_{3}\right): 5.12\left(\mathrm{~s}, 2 \mathrm{H}, \mathrm{CH}_{2}\right)$, $5.60\left(\mathrm{~s}, 2 \mathrm{H}, \mathrm{CH}_{2}\right), 7.11-8.81(\mathrm{~m}, 13 \mathrm{H}, \mathrm{ArH})$. Anal. Calcd for $\mathrm{C}_{26} \mathrm{H}_{18-}$ $\mathrm{FNO}_{4}$ : C, 73.06; H, 4.24; N, 3.28. Found: C, 73.23; H, 4.43; N, 3.12.

\subsubsection{4-[1-(4-Trifluoromethylbenzyl)-5-fluoro-1H-indol-3-yl)-} 3-hydroxyfuran-2(5H)-one (17b)

Mp 209-211 ${ }^{\circ} \mathrm{C}$, yield $42 \% ;{ }^{1} \mathrm{H}$ NMR (DMSO- $d_{6}$ ): 5.10 (s, $2 \mathrm{H}$, $\mathrm{CH}_{2}$ ), 5.67 (s, 2H, $\mathrm{CH}_{2}$ ), 7.08-7.95 (m, 7H, ArH), 8.86 (s, 1H, ArH). Anal. Calcd for $\mathrm{C}_{21} \mathrm{H}_{13} \mathrm{~F}_{4} \mathrm{NO}_{4}$ : $\mathrm{C}, 61.15 ; \mathrm{H}, 3.12 ; \mathrm{N}, 3.34$. Found: $\mathrm{C}$, 61.35; H, 3.08; N, 3.27.

\subsubsection{4-[1-(4-tert-Butylbenzyl)-5-fluoro-1H-indol-3-yl]-3- hydroxyfuran-2(5H)-one (17c)}

Mp 229-231 ${ }^{\circ} \mathrm{C}$, yield 29\%; ${ }^{1} \mathrm{H}$ NMR (DMSO- $d_{6}$ ): $1.23(\mathrm{~s}, 9 \mathrm{H}$, $\left.\mathrm{CH}_{3}\right), 4.87\left(\mathrm{~s}, 2 \mathrm{H}, \mathrm{CH}_{2}\right), 5.42\left(\mathrm{~s}, 2 \mathrm{H}, \mathrm{CH}_{2}\right), 7.00(\mathrm{t}, J=8.8,1 \mathrm{H}, \mathrm{ArH})$, $7.17(\mathrm{~d}, J=8.3,2 \mathrm{H}, \mathrm{ArH}), 7.34(\mathrm{~d}, J=7.1,2 \mathrm{H}, \operatorname{ArH}), 7.51-7.55(\mathrm{~m}$, $1 \mathrm{H}, \mathrm{ArH}), 8.12(\mathrm{~d}, J=9.4,1 \mathrm{H}, \mathrm{ArH}), 10.30(\mathrm{~s}, 1 \mathrm{H}, \mathrm{ArH})$. Anal. Calcd for $\mathrm{C}_{24} \mathrm{H}_{22} \mathrm{FNO}_{4}: \mathrm{C}: 70.75 ; \mathrm{H}: 5.44 ; \mathrm{N}: 3.44$. Found: C: 70.89; $\mathrm{H}$ : 5.23; N: 3.55 .

4.6.10. 4-\{1-[2,4-Bis(trifluoromethyl)benzyl]-5-fluoro- $1 H$-indol3-yl\}-3-hydroxyfuran-2(5H)-one (17d)

Mp 232-234 ${ }^{\circ} \mathrm{C}$, yield 59\%; ${ }^{1} \mathrm{H}$ NMR (DMSO-d ${ }_{6}$ ): 5.19 (s, 2H, $\left.\mathrm{CH}_{2}\right), 5.73\left(\mathrm{~s}, 2 \mathrm{H}, \mathrm{CH}_{2}\right), 6.72-8.54(\mathrm{~m}, 7 \mathrm{H}, \mathrm{ArH})$. Anal. Calcd for $\mathrm{C}_{22-}$ $\mathrm{H}_{12} \mathrm{~F}_{7} \mathrm{NO}_{4}$ : C, 54.22; H, 2.48; N, 2.87. Found: C, 54.46; H, 2.61; N, 2.74 .

\subsubsection{4-[1-(3,5-Dimethylbenzyl)-5-fluoro-1H-indol-3-yl]-3-} hydroxyfuran-2(5H)-one (17e)

Mp 230-232 ${ }^{\circ} \mathrm{C}$, yield 78\%; ${ }^{1} \mathrm{H}$ NMR (DMSO- $d_{6}$ ): 2.21 (s, 6H, $\left.\mathrm{CH}_{3}\right), 5.13\left(\mathrm{~s}, 2 \mathrm{H}, \mathrm{CH}_{2}\right), 5.46\left(\mathrm{~s}, 2 \mathrm{H}, \mathrm{CH}_{2}\right), 6.91-6.95(\mathrm{~m}, 3 \mathrm{H}, \mathrm{ArH})$, 7.12-7.18 (m, 1H, ArH), 7.58-7.62 (m, 1H, ArH), 7.89-7.93 (m, $1 \mathrm{H}, \mathrm{ArH}), 8.68(\mathrm{~s}, 1 \mathrm{H}, \mathrm{ArH})$. Anal. Calcd for $\mathrm{C}_{22} \mathrm{H}_{18} \mathrm{FNO}_{4}$ : C: 69.65; H: 4.78; N: 3.69. Found: C: 69.81; H: 4.92; N: 3.89 .

4.6.12. 4-[1-(2,4,6-Trimethylbenzyl)-5-fluoro- $1 H$-indol-3-yl]-3hydroxyfuran-2(5H)-one (17f)

Mp 202-204 ${ }^{\circ} \mathrm{C}$, yield 44\%; ${ }^{1} \mathrm{H}$ NMR (DMSO- $d_{6}$ ): $2.20(\mathrm{~s}, 6 \mathrm{H}$, $\left.\mathrm{CH}_{3}\right), 2.27\left(\mathrm{~s}, 3 \mathrm{H}, \mathrm{CH}_{3}\right), 4.98\left(\mathrm{~s}, 2 \mathrm{H}, \mathrm{CH}_{2}\right), 5.40\left(\mathrm{~s}, 2 \mathrm{H}, \mathrm{CH}_{2}\right), 6.97$ (s, 2H, ArH), $7.39(\mathrm{~d}, J=8.5,1 \mathrm{H}, \operatorname{ArH}), 7.76(\mathrm{~d}, J=8.5,1 \mathrm{H}, \operatorname{ArH})$, 8.22 (s, $2 \mathrm{H}, \mathrm{ArH}$ ). Anal. Calcd for $\mathrm{C}_{23} \mathrm{H}_{20} \mathrm{FNO}_{4}$ : C: 70.22; $\mathrm{H}: 5.12$; $\mathrm{N}$ : 3.56. Found: C: 70.50; H: 5.23; N: 3.69.

\subsubsection{4-[1-(4-Phenylbenzyl)-5-methoxy-1H-indol-3-yl)-3-} hydroxyfuran-2(5H)-one (18a)

Mp 209-211 ${ }^{\circ} \mathrm{C}$, yield 49\%; ${ }^{1} \mathrm{H}$ NMR (DMSO- $d_{6}$ ): 3.77 (s, $3 \mathrm{H}$, $\left.\mathrm{CH}_{3}\right), 5.15\left(\mathrm{~s}, 2 \mathrm{H}, \mathrm{CH}_{2}\right), 5.55\left(\mathrm{~s}, 2 \mathrm{H}, \mathrm{CH}_{2}\right), 6.86-8.60(\mathrm{~m}, 13 \mathrm{H}, \mathrm{ArH})$. Anal. Calcd for $\mathrm{C}_{27} \mathrm{H}_{21} \mathrm{NO}_{5}: \mathrm{C}, 73.79 ; \mathrm{H}, 4.82 ; \mathrm{N}, 3.19$. Found: C, 73.52; H, 4.61; N, 3.34.

4.6.14. 4-[1-(4-Trifluoromethylbenzyl)-5-methoxy-1H-indol-3yl)-3-hydroxyfuran-2(5H)-one (18b)

Mp 213-215 ${ }^{\circ} \mathrm{C}$, yield 38\%; ${ }^{1} \mathrm{H}$ NMR (DMSO- $d_{6}$ ): $3.76(\mathrm{~s}, 3 \mathrm{H}$, $\left.\mathrm{CH}_{3}\right), 5.10\left(\mathrm{~s}, 2 \mathrm{H}, \mathrm{CH}_{2}\right), 5.62\left(\mathrm{~s}, 2 \mathrm{H}, \mathrm{CH}_{2}\right), 6.85-7.80(\mathrm{~m}, 7 \mathrm{H}, \mathrm{ArH})$, 8.79 (s, $1 \mathrm{H}, \mathrm{ArH}$ ). Anal. Calcd for $\mathrm{C}_{22} \mathrm{H}_{16} \mathrm{~F}_{3} \mathrm{NO}_{5}$ : C, 61.26; $\mathrm{H}, 3.74$; $\mathrm{N}, 3.25$. Found: C, 61.44; H, 3.58; N, 3.39.

4.6.15. 4-[1-(4-tert-Butylbenzyl)-5-methoxy-1H-indol-3-yl]-3hydroxyfuran-2(5H)-one (18c)

Mp 219-221 ${ }^{\circ} \mathrm{C}$, yield $38 \% ;{ }^{1} \mathrm{H}$ NMR (DMSO- $d_{6}$ ): $1.21(\mathrm{~s}, 9 \mathrm{H}$, $\left.\mathrm{CH}_{3}\right), 3.76\left(\mathrm{~s}, 3 \mathrm{H}, \mathrm{OCH}_{3}\right), 5.13\left(\mathrm{~s}, 2 \mathrm{H}, \mathrm{CH}_{2}\right), 5.44\left(\mathrm{~s}, 2 \mathrm{H}, \mathrm{CH}_{2}\right), 6.87$ (d, $J=9.0,1 \mathrm{H}, \operatorname{ArH}$ ), 7.28 (dd, $J=8.5,4 \mathrm{H}, \operatorname{ArH}), 7.49$ (d, $J=9.0,1 \mathrm{H}$, $\operatorname{ArH}), 7.76(\mathrm{~s}, 1 \mathrm{H}, \operatorname{ArH}), 8.59(\mathrm{~s}, 1 \mathrm{H}, \mathrm{ArH})$. Anal. Calcd for $\mathrm{C}_{24} \mathrm{H}_{27} \mathrm{NO}_{5}$ : C: 71.24; $\mathrm{H}: 6.46$; N: 3.32. Found: C: 71.09; H: 6.37; $\mathrm{N}: 3.22$.

4.6.16. 4-\{1-[2,4-Bis(trifluoromethyl)benzyl]-5-methoxy-1Hindol-3-yl\}-3-hydroxyfuran-2(5H)-one (18d)

Mp 223-225 ${ }^{\circ} \mathrm{C}$, yield 68\%; ${ }^{1} \mathrm{H}$ NMR (DMSO- $\left.d_{6}\right): 3.79(\mathrm{~s}, 3 \mathrm{H}$, $\left.\mathrm{OCH}_{3}\right), 5.12\left(\mathrm{~s}, 2 \mathrm{H}, \mathrm{CH}_{2}\right), 5.83\left(\mathrm{~s}, 2 \mathrm{H}, \mathrm{CH}_{2}\right), 6.83-8.13(\mathrm{~m}, 6 \mathrm{H}$, ArH), 8.60 (s, $1 \mathrm{H}, \mathrm{ArH})$. Anal. Calcd for $\mathrm{C}_{23} \mathrm{H}_{15} \mathrm{~F}_{6} \mathrm{NO}_{5}$ : C, 55.32; $\mathrm{H}$, 3.03; N, 2.80. Found: C, 55.29; H, 3.37; N, 2.89.

4.6.17. 4-[1-(3,5-Dimethylbenzyl)-5-methoxy-1H-indol-3-yl]-3hydroxyfuran-2(5H)-one (18e)

Mp 198-200 ${ }^{\circ} \mathrm{C}$, yield 65\%; ${ }^{1} \mathrm{H}$ NMR (DMSO- $\left.d_{6}\right): 2.21(\mathrm{~s}, 6 \mathrm{H}$, $\left.\mathrm{CH}_{3}\right), 3.76\left(\mathrm{~s}, 3 \mathrm{H}, \mathrm{OCH}_{3}\right), 5.15\left(\mathrm{~s}, 2 \mathrm{H}, \mathrm{CH}_{2}\right), 5.41\left(\mathrm{~s}, 2 \mathrm{H}, \mathrm{CH}_{2}\right)$, 6.88-6.93 (m, 4H, ArH), $7.45(\mathrm{~d}, J=8.8,1 \mathrm{H}, \operatorname{ArH}) 7.77(\mathrm{~s}, 1 \mathrm{H}$, ArH), 8.54 (s, $1 \mathrm{H}, \mathrm{ArH})$. Anal. Calcd for $\mathrm{C}_{22} \mathrm{H}_{18} \mathrm{NO}_{5}$ : C: 70.20; $\mathrm{H}$ : 4.82; N: 3.72. Found: C: 70.35; H: 4.99; N: 3.93 .

4.6.18. 4-[1-(2,4,6-Trimethylbenzyl)-5-methoxy-1H-indol-3-yl]3-hydroxyfuran-2(5H)-one (18f)

Mp 191-193 ${ }^{\circ} \mathrm{C}$, yield 52\%; ${ }^{1} \mathrm{H}$ NMR (DMSO-d ${ }_{6}$ ): $2.19(\mathrm{~s}, 6 \mathrm{H}$, $\left.\mathrm{CH}_{3}\right), 2.25\left(\mathrm{~s}, 3 \mathrm{H}, \mathrm{CH}_{3}\right), 3.79\left(\mathrm{~s}, 3 \mathrm{H}, \mathrm{OCH}_{3}\right), 4.96\left(\mathrm{~s}, 2 \mathrm{H}, \mathrm{CH}_{2}\right), 5.34$ $\left(\mathrm{s}, 2 \mathrm{H}, \mathrm{CH}_{2}\right), 6.91-7.01(\mathrm{~m}, 3 \mathrm{H}, \mathrm{ArH}), 7.63(\mathrm{~d}, J=8.8,1 \mathrm{H}, \mathrm{ArH})$, $7.79(\mathrm{~s}, 1 \mathrm{H}, \mathrm{ArH}), 7.94(\mathrm{~s}, 1 \mathrm{H}, \mathrm{ArH})$. Anal. Calcd for $\mathrm{C}_{24} \mathrm{H}_{23} \mathrm{NO}_{5}$ : C: 71.10; H: 5.72; N: 3.45. Found: C: 71.29; H: 5.91; N: 3.63 .

\subsection{Docking studies}

Docking calculations were carried out using the same protocol that we successfully applied in our previous papers, ${ }^{20,34,37,38}$ using Gold software ${ }^{39}$ and GoldScore scoring function.

Regarding docking into the LEDGF/p75 binding pocket, the crystal structure of the dimeric IN $_{\mathrm{CCD}}$ complexed with the LEDGF/ p75 $5_{\text {IBD }}$ was retrieved from the RCSB Protein Data Bank (entry code 2B4J). ${ }^{40}$ The LEDGF structure was removed and hydrogen atoms were added to the IN protein in Discovery Studio 2.5.5. ${ }^{41}$ The standard default settings were used in all calculations. A 20.0 A radius active site was drawn on the original position of the LEDGF $_{I B D}$ dipeptide Ile365-Asp366 and automated cavity detection was used. Results differing by less than $0.75 \AA$ in ligand-all atom RMSD were clustered together. Two rotatable bonds of the diketo acid moiety of the ligands were kept fixed during docking calculation. The two molecules containing the diketo acid moiety were simulated in the mono-ionized form.

Docking studies on IN catalytic site were performed using the crystal structure of PFV-IN with DNA and two Mg ions complexed with the inhibitor raltegravir, retrieved from the RCSB Protein Data Bank (PDB code 3OYA). ${ }^{42}$ Hydrogen atoms were added using Discovery Studio 2.5.5 and the structure of raltegravir was removed. A $15 \AA$ radius active site was defined considering the coordinates of raltegravir in the X-ray position as the centre of the binding pocket.

\subsection{Biological assays}

\subsubsection{LEDGF/p75-HIV-1 integrase interaction screening}

The AlphaScreen assay was performed as previously describe. ${ }^{43}$ Reactions were performed in $25 \mu \mathrm{l}$ final volume in 384-well Optiwell $^{\mathrm{TM}}$ microtiter plates (Perkin-Elmer). The reaction buffer contained $25 \mathrm{mM}$ Tris- $\mathrm{HCl}$ ( $\mathrm{pH} 7.4$ ), $150 \mathrm{mM} \mathrm{NaCl}, 1 \mathrm{mM} \mathrm{MgCl}_{2}$, $0.01 \%(\mathrm{v} / \mathrm{v})$ Tween-20 and $0.1 \%(\mathrm{w} / \mathrm{v})$ bovine serum albumin. His6-tagged integrase ( $300 \mathrm{nM}$ final concentration) was incubated with the compounds at $4{ }^{\circ} \mathrm{C}$ for $30 \mathrm{~min}$. The compounds were added in varying concentrations from 1 up to $100 \mathrm{nM}$. Afterward 
$100 \mathrm{nM}$ of recombinant flag-LEDGF/p75 was added and incubation was extended by another hour at $4{ }^{\circ} \mathrm{C}$. Subsequently, $5 \mu \mathrm{l}$ of $\mathrm{Ni}$-chelate-coated acceptor beads and $5 \mu \mathrm{l}$ of anti-flag donor beads were added to a final concentration of $20 \mu \mathrm{g} / \mathrm{ml}$ of both beads. Proteins and beads were incubated at $30^{\circ} \mathrm{C}$ for $1 \mathrm{~h}$ in order to allow association to occur. Exposure of the reaction to direct light was prevented as much as possible and the emission of light from the acceptor beads was measured in the EnVision plate reader (Perkin-Elmer, Benelux) and analyzed using the EnVision manager software.

\subsubsection{Integrase inhibition}

To determine the susceptibility of the HIV-1 integrase enzyme towards our compounds we used enzyme-linked immunosorbent assays. These assays use an oligonucleotide substrate of which one oligonucleotide (5'-ACTGCTAGAGATTTTCCACACTGACTAAAAGG GTC-3') is labeled with biotin at the $3^{\prime}$ end and the other oligonucleotide is labeled with digoxigenin at the $5^{\prime}$ end. For the overall integration assay the second $5^{\prime}$-digoxigenin labeled oligonucleotide is (5'-GACCCTTTTAGTCAGTGTGGAAAATCTCTAGCAGT-3'). For the Strand Transfer assay the second oligonucleotide lacks GT at the $3^{\prime}$ end. The integrase enzyme was diluted in $750 \mathrm{mM} \mathrm{NaCl}, 10 \mathrm{mM}$ Tris $\mathrm{pH} 7.6,10 \%$ glycerol and $1 \mathrm{mM} \beta$-mercapto ethanol. To perform the reaction $4 \mu$ ldiluted integrase (corresponding to a concentration of $1.6 \mu \mathrm{M}$ ) and $4 \mu \mathrm{l}$ of annealed oligonucleotides ( $7 \mathrm{nM}$ ) were added in a final reaction volume of $40 \mu \mathrm{l}$ containing $10 \mu \mathrm{M} \mathrm{MgCl}_{2}, 5 \mu \mathrm{M}$ DTT, $20 \mu \mathrm{M}$ HEPES pH 7.5, 5\% PEG and 15\% DMSO. The reaction was carried out for $1 \mathrm{~h}$ at $37^{\circ} \mathrm{C}$. Reaction products were denatured with $30 \mathrm{mM} \mathrm{NaOH}$ and detected by an immunosorbent assay on avidin coated plates. ${ }^{44}$

\subsubsection{In vitro anti-HIV and drug susceptibility assays}

The inhibitory effect of antiviral drugs on the HIV-induced cytopathic effect (CPE) in human lymphocyte MT-4 cell culture was determined by the MT-4/MTT-assay. ${ }^{45}$ This assay is based on the reduction of the yellow colored 3-(4,5-dimethylthiazol-2-yl)-2,5diphenyltetrazolium bromide (MTT) by mitochondrial dehydrogenase of metabolically active cells to a blue formazan derivative, which can be measured spectrophotometrically. The 50\% cell culture infective dose $\left(\mathrm{CCID}_{50}\right)$ of the $\mathrm{HIV}\left(\mathrm{III}_{\mathrm{B}}\right)$ strain was determined by titration of the virus stock using MT- 4 cells. For the drug-susceptibility assays, MT-4 cells were infected with $100-300$ CCID $_{50}$ of the virus stock in the presence of fivefold serial dilutions of the antiviral drugs. The concentration of the various compounds that achieved 50\% protection against the CPE of the different HIV strains, which is defined as the $\mathrm{EC}_{50}$, was determined. In parallel the $50 \%$ cytotoxic concentration $\left(\mathrm{CC}_{50}\right)$ was determined.

\section{Acknowledgment}

This work was supported by THINC Project (European Commission HEALTH-F3-2008-201032).

\section{References and notes}

1. Www.UNAIDS.org.

2. Palella, F. J., Jr.; Delaney, K. M.; Moorman, A. C.; Loveless, M. O.; Fuhrer, J. Satten, G. A.; Aschman, D. J.; Holmberg, S. D. N. Eng. J. Med. 1998, 338, 853.

3. van Sighem, A. I.; Gras, L. A.; Reiss, P.; Brinkman, K.; de Wolf, F. AIDS 2010, 24 1527.

4. Mills, E. J.; Bakanda, C.; Birungi, J.; Chan, K.; Ford, N.; Cooper, C. L.; Nachega, J. B. Dybul, M. Hogg R. S. Lancet 2008, 372, 293.

5. Juday, T.; Gupta, S.; Grimm, K.; Wagner, S.; Kim, E. HIV Clin. Trials 2011, 12, 71.

6. Ammassari, A.; Trotta, M. P.; Shalev, N.; Marconi, P.; Antinori, A. Antiviral Ther. 2012, 17, 785.

7. Broder, S.; Fauci, A. S. Public Health Rep. 1988, 103, 224
8. listed, N. a. AIDS alert 2009, 24, 106

9. Cooper, D. A.; Steigbigel, R. T.; Gatell, J. M.; Rockstroh, J. K.; Katlama, C.; Yeni, P.; Lazzarin, A.; Clotet, B.; Kumar, P. N.; Eron, J. E.; Schechter, M.; Markowitz, M.; Loutfy, M. R.; Lennox, J. L.; Zhao, J.; Chen, J.; Ryan, D. M.; Rhodes, R. R.; Killar, J. A.; Gilde, L. R.; Strohmaier, K. M.; Meibohm, A. R.; Miller, M. D.; Hazuda, D. J.; Nessly, M. L.; DiNubile, M. J.; Isaacs, R. D.; Teppler, H.; Nguyen, B. Y. N. Eng. J. Med. 2008, 359, 355.

10. Steigbigel, R. T.; Cooper, D. A.; Teppler, H.; Eron, J. J.; Gatell, J. M.; Kumar, P. N.; Rockstroh, J. K.: Schechter, M.; Katlama, C.; Markowitz, M.; Yeni, P.; Loutfy, M. R.; Lazzarin, A.; Lennox, J. L.; Clotet, B.; Zhao, J.; Wan, H.; Rhodes, R. R.; Strohmaier, K. M.; Barnard, R. J.; Isaacs, R. D.; Nguyen, B. Y. Clin. Infect. Dis. 2010, 50, 605 .

11. Malet, I.; Delelis, O.; Valantin, M. A.; Montes, B.; Soulie, C.; Wirden, M.; Tchertanov, L.; Peytavin, G.; Reynes, J.; Mouscadet, J. F.; Katlama, C.; Calvez, V.; Marcelin, A. G. Antimicrob. Agents Chemother. 2008, 52, 1351.

12. Shimura, K.; Kodama, E.; Sakagami, Y.; Matsuzaki, Y.; Watanabe, W.; Yamataka, K.; Watanabe, Y.; Ohata, Y.; Doi, S.; Sato, M.; Kano, M.; Ikeda, S.; Matsuoka, M. J. Virol. 2008, 82, 764

13. Zolopa, A. R.; Berger, D. S.; Lampiris, H.; Zhong, L.; Chuck, S. L.; Enejosa, J. V: Kearney, B. P.; Cheng, A. K. J. Infect. Dis. 2010, 201, 814.

14. Quashie, P. K.; Sloan, R. D.; Wainberg, M. A. BMC Med. 2012, 10, 34.

15. Garrido, C.; Soriano, V.; Geretti, A. M.; Zahonero, N.; Garcia, S.; Booth, C.; Gutierrez, F.; Viciana, I.; de Mendoza, C. Antiviral Res. 2011, 90, 164.

16. Min, S.; Sloan, L.; DeJesus, E.; Hawkins, T.; McCurdy, L.; Song, I.; Stroder, R.; Chen, S.; Underwood, M.; Fujiwara, T.; Piscitelli, S.; Lalezari, J. AIDS 2011, 25, 1737.

17. Saag, S. Top. Antiviral Med. 2012, 20, 162.

18. De Luca, L.; Barreca, M. L.; Ferro, S.; Christ, F.; Iraci, N.; Gitto, R.; Monforte, A. M.; Debyser, Z.; Chimirri, A. ChemMedChem 2009, 4, 1311.

19. De Luca, L.; Ferro, S.; Gitto, R.; Barreca, M. L.; Agnello, S.; Christ, F.; Debyser, Z.; Chimirri, A. Bioorg. Med. Chem. 2010, 18, 7515.

20. De Luca, L.; Gitto, R.; Christ, F.; Ferro, S.; De Grazia, S.; Morreale, F.; Debyser, Z.; Chimirri, A. Antiviral Res. 2011, 92, 102.

21. Busschots, K.; Voet, A.; De Maeyer, M.; Rain, J. C.; Emiliani, S.; Benarous, R.; Desender, L.; Debyser, Z.; Christ, F. J. Mol. Biol. 2007, 365, 1480.

22. Al-Mawsawi, L. Q.; Neamati, N. ChemMedChem 2011, 6, 228.

23. Garcia-Rivera, J. A.; Bueno, M. T.; Morales, E.; Kugelman, J. R.; Rodriguez, D. F.; Llano, M. J. Virol. 2010, 84, 740.

24. Greene, W. C.; Debyser, Z.; Ikeda, Y.; Freed, E. O.; Stephens, E.; Yonemoto, W.; Buckheit, R. W.; Este, J. A.; Cihlar, T. Antiviral Res. 2008, 80, 251.

25. Zhang, H.; Curreli, F.; Waheed, A. A.; Mercredi, P. Y.; Mehta, M.; Bhargava, P.; Scacalossi, D.; Tong, X.; Lee, S.; Cooper, A.; Summers, M. F.; Freed, E. O.; Debnath, A. K. Retrovirology 2013, 10, 136.

26. Esposito, F.; Tramontano, E. Antiviral Chem. Chemother 2014, 23(4), 129.

27. Di Santo, R. J. Med. Chem. 2014, 57(3), 539.

28. Costi, R.; Metifiot, M.; Esposito, F.; Cuzzucoli Crucitti, G.; Pescatori, L.; Messore, A.; Scipione, L.; Tortorella, S.; Zinzula, L.; Novellino, E.; Pommier, Y. Tramontano, E.; Marchand, C.; Di Santo, R. J. Med. Chem. 2013, 56(21), 8588.

29. De Luca, L.; De Grazia, S.; Ferro, S.; Gitto, R.; Christ, F.; Debyser, Z.; Chimirri, A. Eur. J. Med. Chem. 2011, 46, 756.

30. Ferro, S.; De Luca, L.; Barreca, M. L.; De Grazia, S.; Christ, F.; Debyser, Z.; Chimirri, A. Bioorg. Med. Chem. 2010, 18, 5510.

31. Ferro, S.; De Luca, L.; Barreca, M. L.; Iraci, N.; De Grazia, S.; Christ, F.; Witvrouw, M.: Debyser, Z.; Chimirri, A. J. Med. Chem. 2009, 52, 569.

32. Ferro, S.; Barreca, M. L.; De Luca, L.; Rao, A.; Monforte, A. M.; Debyser, Z.; Witvrouw, M.; Chimirri, A. Arch. Pharm. 2007, 340, 292.

33. De Luca, L.; Ferro, S.; Morreale, F.; Christ, F.; Debyser, Z.; Chimirri, A.; Gitto, R. J. Enzyme Inhib. Med. Chem. 2013, 28, 1002.

34. De Luca, L.; Morreale, F.; Chimirri, A. J. Chem. Inf. Model. 2012. http://dx.doi.org/ 10.1021/ci300361e.

35. Barreca, M. L.; Ferro, S.; Rao, A.; De Luca, L.; Zappala, M.; Monforte, A. M.; Debyser, Z.; Witvrouw, M.; Chimirri, A. J. Med. Chem. 2005, 48, 7084.

36. Ferro, S.; Grazia, S. D.; De Luca, L.; Gitto, R.; Faliti, C. E.; Debyzer, Z.; Chimirri, A. Molecules 2011, 16, 6858.

37. De Luca, L.: Morreale, F.; Christ, F.; Debyser, Z.; Ferro, S.; Gitto, R. Eur. J. Med. Chem. 2013, 68C, 405.

38. Ferro, S.; De Luca, L.; Morreale, F.; Christ, F.; Debyser, Z.; Gitto, R.; Chimirri, A. J. Enzyme Inhib. Med. Chem. 2013.

39. Jones, G.; Willett, P.; Glen, R. C.; Leach, A. R.; Taylor, R. J. Mol. Biol. 1997, 267. 727.

40. Cherepanov, P.; Ambrosio, A. L.; Rahman, S.; Ellenberger, T.; Engelman, A. Proc. Natl. Acad. Sci. U.S.A. 2005, 102, 17308.

41. Accelrys, Discovery Studio.

42. Hare, S.; Vos, A. M.; Clayton, R. F.; Thuring, J. W.; Cummings, M. D.; Cherepanov, P. Proc. Natl. Acad. Sci. U.S.A. 2010, 107, 20057.

43. Al-Mawsawi, L. Q.; Christ, F.; Dayam, R.; Debyser, Z.; Neamati, N. FEBS Lett. 2008, 582, 1425.

44. Christ, F.; Voet, A.; Marchand, A.; Nicolet, S.; Desimmie, B. A.; Marchand, D. Bardiot, D.; Van der Veken, N. J.; Van Remoortel, B.; Strelkov, S. V.; De Maeyer, M.; Chaltin, P.; Debyser, Z. Nat. Chem. Biol. 2010, 6, 442.

45. Pauwels, R.; Balzarini, J.; Baba, M.; Snoeck, R.; Schols, D.; Herdewijn, P.; Desmyter, J.; De Clercq, E. J. Virol. Methods 1988, 20, 309. 